Equities' Exposures to Currencies: beyond the loglinear model

Kris Boudt, Fang Liu and Piet Sercu

DEPARTMENT OF ACCOUNTANCY, FINANCE AND INSURANCE (AFI) 


\title{
Equities' Exposures to Currencies: beyond the loglinear model ${ }^{*}$
}

\author{
Kris Boudt ${ }^{\dagger}$, Fang Liu ${ }^{\ddagger}$ and Piet $\mathrm{Sercu}^{\S}$, \\ Project started in February 2011; this draft formatted at 17:52 on Wednesday $29^{\text {th }}$ February, 2012. \\ Preliminary - comments welcome
}

*All remaining errors are the authors'. Financial support from the Dutch science foundation is gratefully acknowledged.

${ }^{\dagger}$ K.U.Leuven/Lessius and V.U.University Amsterdam; kris.boudt@econ.kuleuven.be

${ }^{\ddagger}$ Central University for Finance and Economics, Beijing, fliu@cufe.edu.cn

${ }^{\S}$ K.U. Leuven, Faculty of Business and Economics and UCLouvain, Louvain School of Business; piet.sercu@econ.kuleuven.be. 


\begin{abstract}
It has been surprisingly difficult to demonstrate non-zero currency exposures for individual stocks, and a recent study even finds that the absolute value of estimated exposure is a better predictor than the value itself. We argue that the value of the international-trade option should be convex in the exchange rate so that exposure depends on the exchange rate level. Since spot rates move slowly, exposure could then differ substantially across samples. Many large companies, in addition, must be ambidextrous - positively exposed in some activities, and negatively in others. We derive a class of tractable regression models and find that the standard loglinear regression is invariably beaten by the proposed alternative. However, too often we detect at least a partial concavity.
\end{abstract}

Keywords: Forex, exposure, real options, threshold model. JEL-codes: C13, C22, G11. 


\section{Equities' exposures to currencies: beyond the loglinear model}

\section{Introduction and Summary}

It seems self-evident that exporters benefit from a depreciation of the currency of their export markets: if they are price takers abroad, their profit margin swells, and if they have some market power they can further improve the results by optimally lowering the foreign sales price. Thus, in a regression of stock returns on percentage changes on the exchange rate, ${ }^{1}$ the slope coefficient should be positive. By a similar argument, importers should be characterized by negative exposures. Yet, as we document in Section 1, it has been surprisingly difficult to demonstrate non-zero currency exposures for individual stocks, especially if one tries to link the sign of the exposure to e.g. the firm's net trade. Priestley and Odegaard (2007) find that exposure seems to change sign depending on the exchange-rate's direction of change. More generally, estimated exposures seem quite unstable. Our aim is to to solve both puzzles.

The core ingredient in this paper is that the notion of constant exposure, whether defined as a partial derivative or an elasticity, can probably be improved upon; that is, we question linearity or loglinearity in levels. Instead, we expect a non-homothetic convex relationship between the firm's value and the real exchange rate (Sercu, 2009, pp 460-461). In cash flow terms, a linear relation would hold only if both the foreign price and production plan remain unaltered regardless of the exchange rate, but that does rarely make sense. Because of the firm's option to adjust pricing and production, the impact of adverse movements can be partially mitigated, and beneficial changes can be exploited further, as already illustrated above for the case of an exporter.

One may rightly object that the above cash-flow picture ignores lump-sum adjustment costs. Especially at the export side, abandoning or re-entering a market is likely to require one-off outlays that are largely irreversible. Lump-sum items do destroy the smoothness of the cash-flow function. But those discontinuities disappear again if we consider not the future cash flows themselves but their PV. In terms of market value, the metric studied in all empirical

\footnotetext{
${ }^{1}$ Throughout the article, the term exchange rate refers to the value of the foreign currency in units of home currency.
} 
work, optimal dynamic management of the option to abandon or re-enter a market implies that, for lower and lower exchange rates, the value of an export business smoothly converges towards its liquidation value, or to the value of the firm as a purely domestic entity if this is the better alternative. ${ }^{2}$ One oft-cited example is International Harvester, which abandoned its export markets after the Reagan dollar hike, and for decades essentially fell back on the U.S. local market. The same holds for an option to import: its value should smoothly shrink with higher and higher real exchange rates for the source country. Thus, in value terms we should still get smooth convex relations even if exercising the real options requires irreversible lump-sum investments. The amended bottom line is that exposure depends on the level of the real exchange rate, a feature missed by the usual loglinear model that is behind the linear regression of returns on percentage changes in exchange rates.

A second ingredient of our approach that the real exchange rate typically exhibits very little mean-reversion. If, once it arrives at a particular level, the rate stays in that neigborhood for a rather long term and if every neighborhood has its own exposure, then if one estimates exposures from different subperiods one could observe very different results.

Two elements could further complicate the view that was just proposed. First, the above story is about an unhedged firm. But many firms do hedge their transaction exposures and their expected cash flows over a chosen horizon. In the mythical case of a linear relation between cashflow $C$ and exchange rate $S$, all exposures within the hedging horizon can be eliminated by a forward hedge. But if the relation is convex, as we just argued it should, a static linear hedge merely flips a convex schedule into a lopsided U. Only if the firm hedges its entire value, if the exchange rate's path is smooth, and if there is continuous dynamic updating, can the relation between value and exchange rate disappear altogether. While few firms are that ambitious, it is unclear how far they go, so the realized relation may be a sequence of ever-shifting inverse U-shapes that defies easy modeling.

The second element that could similarly obfuscate the situation is that the familiar exporter/importer dichotomy may be outdated. Nowadays, most trade is organized inside multi-

\footnotetext{
${ }^{2}$ When the exchange rate approaches the critical level where the firm would optimally switch its operating mode, the likelihood that the fixed adjustment cost will actually occur will smoothly approach the certainty level, so the stock price smoothly adjusts. Smooth pasting as a characteristic of optimization was introduced by Merton (1973). Dixit (198 ) offers an excellent discussion. Sercu and Van Hulle (1992) apply it to the value of an exporting firm, with a 'mothballing' mode between the active-plant mode and the liquidation mode.

Note that considering values instead of cash flows does not entirely solve the problem of lump-sum switch costs. If there are fixed costs to suspend and re-enter a market, the value function still depends on whether one is actively trading or not. We have to ignore this 'hystereris' refinement.
} 
national corporations or corporate groups, and these corporations produce and sell worldwide. Most trading firms do have a sizable home activity, of course, which may have low exposure. In addition, many firms may run both import- and export-like divisions or activities. This makes the firm ambidextrous - positively exposed in some activities, and negatively in others. While these distinct exposures are probably occuring for different currencies, the fact is that most studies, since Jorion (1990), use a currency index. Thus, the test really is not a particular bilateral rate but about the effect of a de- or appreciation of the home currency against the rest of the world. When the average foreign currency rises (i.e. the dollar weakens, in the case of a U.S. firm), the typical U.S. multinational's export-like business florish while its import-related activities are hurt. If the separate relations had been linear, the total value would still be linear in the exchange rate and have an unambiguous net slope, positive or negative depending on which business dominates. But with convexity, total value may become a U-shaped function of the exchange rate, with an exposure that has both positive and negative zones next to a potentially important domain with near-zero exposure. ${ }^{3}$ Again, with long memory in the exchange-rate path, depending on the sample one might find positive, or negative, or zero exposures.

\section{Currency exposure: a review of earlier empirical work}

One antecedent of the standard loglinear regression is the Johnson (1960) and Stein (1961) minimum-variance hedge problem: if a cash flow or asset worth $y$ is to be hedged using an instrument with value $x$, then the regression coefficient $b$ in $y=a+b x+e$ is the hedge ratio that minimizes the residual variance of $y$, that is, the value hedged. Dumas (1978), reiterated in Adler and Dumas (1984), imported this concept into international finance, choosing the future exchange rate as the $x$ variable, and naming this regression coefficient $y$ 's exposure to the exchange rate.

If time series data are used and both $y$ and $x$ are nonstationary, or close to, then the

\footnotetext{
${ }^{3}$ While exposures at the individual-firm level are often computed for their own sake, in asset-pricing tests the test data are typically portfolio returns. To test international CAPMs, for instance, one often works with country indices, or three- or four-factor stratified portfolios, or country $\times$ industry aggregates. Even if few firms are really ambidextrous individually, this characteristic is still more likely to emerge at an aggregate level. The convexity effect at the company level then also induces changing weights. For instance, if the home currency depreciates, export-like firms florish and obtain higher weights at the expense of import-like companies, reinforcing the rise in the exposure. While the formal arguments developed below employ a company vocabulary, the exploratory empirical work is actually done on industry index data.
} 
regression has to work with first-differenced numbers, at the very least. Actually, to reduce heteroscedasticity issues, the preferred version is to work with percentage changes rather than dollar changes, implying that the regression coefficient delivers an elasticity rather than the partial-derivative-like number (like a hedge ratio). If excess returns are used, the regression is

$$
\left(\tilde{r}_{j}-r_{d}\right)=\delta_{j}+\gamma_{j}\left(\tilde{s}+r_{f}-r_{d}\right)+e_{j}
$$

where $\tilde{r}_{j}$ denotes the return on a risky asset $j ; r_{d}\left(r_{f}\right)$ is the domestic (foreign) risk-free rate; and $\tilde{s}$ the simple percentage change in the exchange rate, typically expressed in home currency units. In most cases, the risk-free rates are omitted without any noticeable harm. In doing so, the exposure literature followed the CAPM-inspired market-model regression,

$$
\left(\tilde{r}_{j}-r_{d}\right)=\alpha_{j}+\beta_{j}\left(\tilde{r}_{m}-r_{d}\right)+e_{j}
$$

where $\tilde{r}_{m}$ denotes the market-index return.

A more direct link with asset pricing theory emerged when Sercu (1980), generalizing Solnik's (1973) International CAPM, realized that Dumas' exposures, in their multivariate guise, could be used to develop a quasi one-factor CAPM for stocks hedged against exchange risk. Adler and Dumas (1983) estimate the equation. In an alternative version, Sercu (1980) merges the CAPM for bonds with that for hedged stocks into a standard multifactor CAPMcum-regression, where the market portfolio shows up next to the exchange-rate changes of all countries. In the two-country case, for instance, the model is

$$
\mathrm{E}\left(\tilde{r}_{j}-r_{d}\right)=\beta_{j}^{\prime} \mathrm{E}\left(\tilde{r}_{w}-r_{d}\right)+\gamma_{j}^{\prime} \mathrm{E}\left(s+r_{f}-r_{d}\right)
$$

where $\tilde{r}_{w}$ denotes the return on the world market $w$ and where $\beta_{j}^{\prime}$ and $\gamma_{j}^{\prime}$ are the trivariate slope coefficients from

$$
\left(\tilde{r}_{j}-r_{d}\right)=\beta_{j}^{\prime}\left(\tilde{r}_{w}-r_{d}\right)+\gamma_{j}^{\prime}\left(\tilde{s}+r_{f}-r_{d}\right)+e_{j}
$$

In multi-country models, each and every exchange rates percentage change shows up in the CAPM and in its associated regression as a separate regressor.

Since Jorion (1990), these separate, bilateral exchange-rate changes are often replaced by a single return on a bucket of currencies, typically trade-weighted. Again, in most applications the risk-free rates are omitted from the regression; in practice, lastly, the world market is often replaced by stock $j$ s home-country market index return, denoted $\tilde{r}_{m_{j}}$. The motivation is to reconcile the Dumas regression with the national market model, often still seen as the premier 
return-generating model, and to obtain more precision by controlling for a host of factors that affect all stocks in similar ways. The Jorion regression, in short, is

$$
\tilde{r}_{j}=\beta_{j}^{\prime} \tilde{r}_{m_{j}}+\gamma_{j}^{\prime} \bar{s}+e_{j}
$$

with $\overline{\tilde{s}}$ denoting the percentage price change for the basket, an average of the currency-bycurrency percentage price changes.

Most of the subsequent literature has worked with variants of this regression. Much of the tinkering was motivated by the, in a way, disappointing results for the model: with U.S. data, surprisingly few companies came up with significant exposures (see e.g. Jorion 1990, 1991; Bodnar and Gentry, 1993; Amihud, 1994; Choi and Prasad, 1995). Non-U.S. data, from supposedly more open countries, provided mixed results: He and $\mathrm{Ng}$ (1998) report one stock out of four to be exposed in Japan, and Kiymaz (2003) one out of two for Turkey, but others found only weak evidence of currency exposure for Australia (Khoo, 1994) or broad samples of countries including Japan (Griffin and Stulz, 2001; Dominguez and Tesar, 2006. Chue and Cook (2008) estimate the exposure of emerging countries and find the depreciation of domestic currencies has a negative impact on stock returns.

All of these studies look at stocks as priced in their home stock market. Translated asset prices, however, in the sense of assets where most or all the price-setting happens in the foreign market, are clearly exposed; see e.g. Jorion's results for foreign multinationals listed in the U.S., or Adler, Dumas and Simon's (1986) findings for dollar returns on foreign market indices. Thus, the picture seems to be disconcertingly close to Solnik's original CAPM, where each stock has a clear nationality in the sense that its value, when expressed in its home currency, moves independently of exchange rates against that home currency.

This may reflect systematic and successful covering against exchange risk. Multinationals can do so via long-run operational hedges (Logue, 1995; Bartam, Brown and Minton, 2010) or via financial hedges. To test this, exposures $\gamma$ have been modeled as linear in variables that probably correlate with the firm's desire to hedge, like the firm's foreign sales or operations as a fraction of the total, the fraction of exports and imports, its leverage, its liquidity, and so on. There is some evidence that firms that have higher operating exposures or are more vulnerable do hedge more, resulting in a lower residual exposure; but the effect is not strong (Allayannis, 1995; Goa, 2000; Pantzalis, 2001; Carter, Pantzalis and Simkins , 2001; Williamson, 2001; De Jong, Ligterink, and Macrae, 2002; Crabb, 2002). A related literature relates the gammas to firm characteristics, sometimes with some success (Bodnar and Gentry, 1993; Williamson, 
2001) and sometimes without much useful insights (Amihud, 1994; Fraser and Pantzalis, 2004).

Exposure may also be unstable. Many authors run subperiod regressions (Jorion, 1990; Amihud, 1995; He and Ng, 1998; Glaum, Brunner and Holger, 2000; Williamson, 2001; Doukas, Hall and Lang, 2003), or work with rolling or moving data windows (Glaum, 2000; Entorf and Jamin, 2002, 2007), or relate changes in exposure to the shifting weight of exports and imports (Allayannis, 1995).

Regarding the data type, there may be an intervalling effect. Some report better results when using daily data rather than the usual monthly (Chamberlain, Howe and Popper, 1997; Di Ioro and Faff, 2000; Glaum, Brunner and Holger, 2000), while others advocate longer holding periods (Bartov and Bodnar, 1994; Chow, Lee and Solt, 1997; Chow and Chen, 1998; Griffin and Stulz, 2001; Dominguez and Tesar, 2001; Di Ioro and Faff, 2000; Muller and Verschoor, 2006). Even adding lagged exchange-rate changes has been considered (Bartov and Bodnar, 1994; Allayannis, 1996) with mixed results.

Others have tweaked the input data. Regarding the market return, Bodnar and Wong (2003) experiment with equal versus value weighting. Others replace the market by a number of macro variables (Gao, 2000), return determinants (Chow and Chen, 1998) or Fama-French factors (Doukas, Hall and Lang, 1999). A branch of research has worked with orthogonalized regressors, either constructing in-sample-hedged $\tilde{r}_{m}$ variates (Kiymaz, 2003) or market-corrected $\tilde{s}$ data (Elton and Gruber, 1991; Choi and Prasad, 1995). The effect of using this particular type of constructed variables is that the coefficient of the undoctored regressor becomes equal to the simple regression slope, while the coefficient of the orthogonalized regressor remains equal to the multiple-regression slope (the Frisch-Waugh (1933) theorem). Undesirably, however, the regular t-statistics no longer apply, so this is not a recommendable procedure.

Much attention has been given to the exchange-rate variable, especially to the use of a fixed basket $\grave{a}$ la Jorion. The objective is to avoid multicollinearity between the various exchange rate changes, which all share a common component (the reference-currency factor). There would be no loss of information if all firms have bilateral exposures to the various currencies that are proportional to the weights used in the basket. This is unlikely, of course: firms trade with different countries, chose their own selective hedging policies, face different demand elasticities depending on their industry etc. So if the implicit assumption of proportional exposures is not met, the use of a basket comes at a cost: the regressor measures the ideal basket with error, inducing a standard attenuation-towards-zero bias. Domingues and Tesar (2001b) find that using bilateral rates beats the currency basket. Similarly, some obtain better results when 
multiple, more focused buckets are used, constructed e.g. via factor analysis (Miller and Reuer, 1998) or on a regional basis (Muller and Verschoor, 2006). Khoo (1994) collects firm-by-firm trade data and builds a firm-specific basket. This is unusually painstaking, but still ignores other determinants of exposure, like demand elasticity and hedging policies. A last issue is whether one should not use real returns, and changes in the real exchange rate, rather than nominal units. In practice, using real data hardly affects the conclusions (Bodnar and Gentry, 1993). Nor do two-step procedures where the variates are first regressed on lagged variables with some predictive power, like lagged changes (Amihud, 1994) or macro variables (Gao, 2000) to filter out the predictable part of changes.

A last point of debate has been the use of portfolio data versus individual stock data as the left-hand side variable. The attraction of aggregate data is that there is likely to be diversification, meaning a lower total variance and, it is hoped, especially a lower residual variance, implying more precise estimates. In addition, one can easily build balanced panels without creating a survivalship-biased sample, as one would have to do with individual stock data. The obvious risk is firm heterogeneity: if the component stocks have different exposures, and specially of their gammas differ in sign, the resulting aggregate may have too little exposure to be detectable. Many authors, on balance, come down against portfolios (Allayannis, 1994, 1996; Khoo, 1994; Choi and Prasad, 1995; Muller and Verschoor, 2006). Yet the context of the test matter too. For a stand-alone exercise, individual stock data may be recommendable. But for CAPM tests, portfolio data are much more wieldy. Griffin and Stulz (2001), Dumas and Solnik (1995) and De Santis and Gerard (1998), for instance, work with country indices. In this paper we adopt a compromise, working with industry portfolios per country: these are likely to be less heterogenous than country

There are some disconcerting results, like when $\mathrm{He}$ and $\mathrm{Ng}$ (1998) and Dominguez and Tesar (2006) find the direction of exposure depends on specific exchange rate level or when Priestley and Odegaard (2007) find a nonlinear relation where exchange rate exposure changing in terms of depreciation to appreciation periods. By and large, though, the empirical literature has barely ventured beyond the simple loglinear model, even though theoretical work suggests much richer models. Our ambition is to reduce the gap between theory and empirics by presenting a model whose features are inspired by theory but whose mathematical form is amenable to empirical work. 


\section{The Regression Models}

\subsection{A Real-option Model for an Unhedged Ambidextrous Corporation}

For generality we consider a firm that has divisions with different exposures. Some of the exposures may be positive, like in exporting or import-substituting activities (subscript $x$ ), or zero, like in a domestic division in a sheltered sector (subscript $d$ ), or negative, such as in activities that rely on imported inputs or have the option to import instead of buying or producing locally (subscript $m$ ). The firm may not be active in more than one of these at all times: the three activities are options that are exercised only when it makes sense. The functional form between the firm's value and the exchange rate should capture the smoothness characteristic suggested by the real options literature and should also allow a tractable transition to a test equation. To that end we approximate the value of each exposed division (or group of divisions) by a piecewise quadratic in $S .{ }^{4}$ Denote the level of the real exchange rate at which the firm decides to abandon its export-like activities by $\underline{S}_{x, t}$, and the alternative value of that division by $\gamma_{x, t}{ }^{5}$ This alternative value may be a liquidation value. More plausibly, the firm also has domestic activities, in which case the best alternative use of the former export-market assets may be to switch them to domestic use; then the alternative value $\gamma_{x, t}$ is a component of the domestic-asset value. A simple model for the positive-exposure or export-like activities, offering both smoothness and tractability, then is

$$
V_{x, t}=\gamma_{x, t}+\delta_{x, t}\left(S_{t}-\underline{S}_{x, t}\right)_{+}^{2},
$$

where $\delta_{x, t}$ is nonnegative and $\left(S_{t}-\underline{S}_{x, t}\right)_{+}^{2}$ is short for $\left[\operatorname{Max}\left(S_{t}-\underline{S}_{x, t}, 0\right)\right]^{2}$. Like a quadratic spline this is a smoothly changing piecewise function - except that (i) the knot point $\underline{S}_{x, t}$ is estimated rather than pre-set by the researcher, and (ii) we join a linear and a quadratic rather than two quadratics. We label this a semi-spline regression. A similar relation then holds for the negative-exposure or import-like divisions:

$$
V_{m, t}=\gamma_{m, t}+\delta_{m, t}\left(S_{t}-\underline{S}_{m, t}\right)_{-}^{2}
$$

\footnotetext{
${ }^{4}$ An equivalent approach would be to leave the function unspecified and then take a quadratic approximation for the changes.

${ }^{5}$ Subscripts $j$ for the firm, in $V, \underline{S}_{x, t}, \underline{S}_{m, t}, \gamma_{x, t}, \delta_{x, t}, \gamma_{m, t}$ and $\delta_{m, t}$ have been suppressed for ease of reading, but all these numbers are really firm-specific.
} 
Figure 1: The Value of the Firm as a Function of the Real Exchange Rate

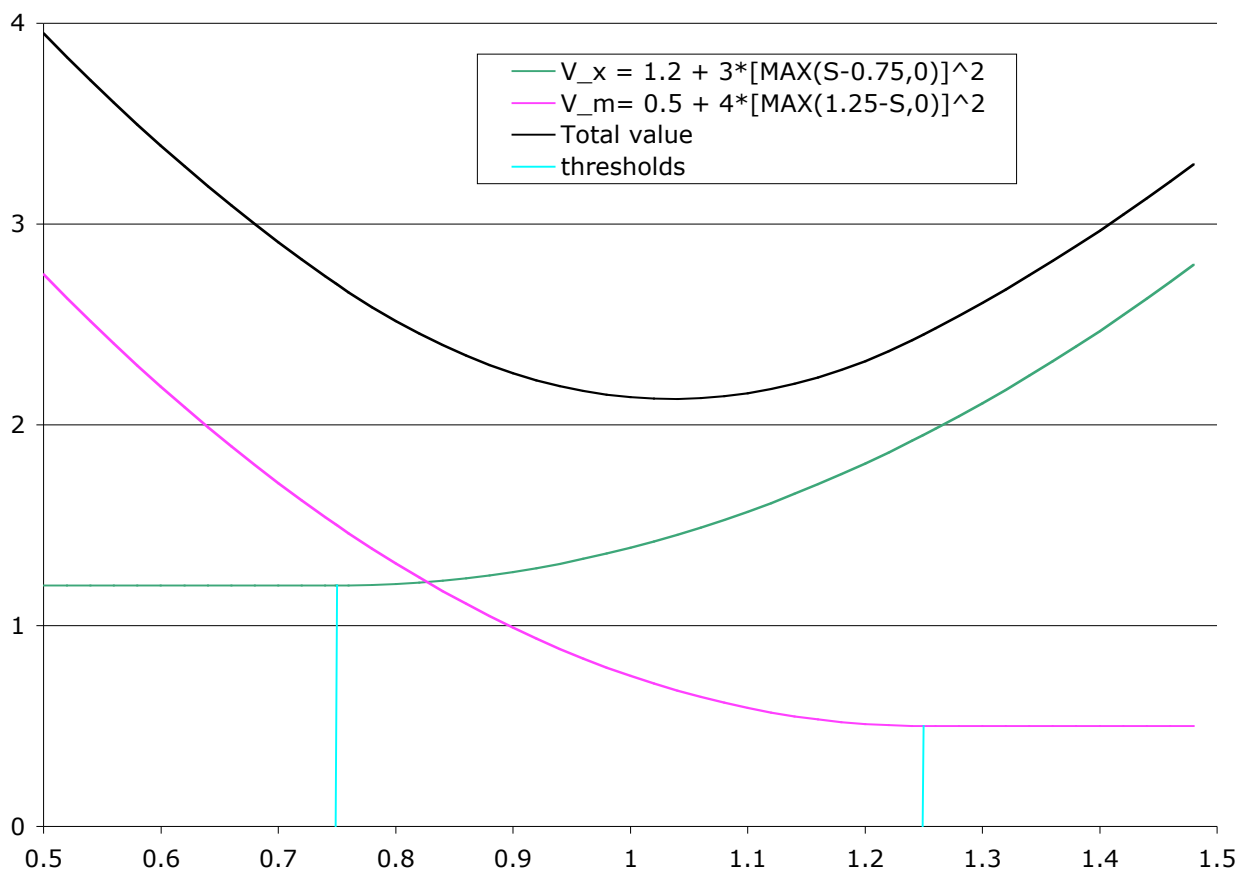

Source The option values for the $x$ - and $m$-divisions upon liquidation are are 1.2 and 0.5 , respectively, and the divisions decide to suspend at a real rate of 1.25 for the import sections and 0.75 for the export activities. The total value does not include the unexposed ('home') activities. if any.

where $\delta_{m, t}$ is nonnegative ${ }^{6}$ and $\left(S_{t}-\underline{S}_{x, t}\right)_{-}^{2}$ is short for $\left[\operatorname{Min}\left(S_{t}-\underline{S}_{x, t}, 0\right)\right]^{2}$. Lastly there may be domestic activities, whose value changes we model via the market model, see below.

For the sake of generality, we consider a potentially ambidextrous firm; in what follows, one can always set one of the $\delta$ s equal to zero to find the monodextrous case. Summing the two exposed divisions' values, we obtain a total exposed value of

$$
V_{t}=\left[\gamma_{x, t}+\gamma_{m, t}\right]+\delta_{x, t}\left(S_{t}-\underline{S}_{x, t}\right)_{+}^{2}+\delta_{m, t}\left(S_{t}-\underline{S}_{m, t}\right)_{-}^{2}
$$

Figure 1 illustrates this. In the example, the liquidation values for the import and export divisions' assets equal 1.2 and 0.5, respectively. Scrapping the export business is optimal when rates fall to 0.75 or lower; for the import-related activities, liquidation is rational for rates equal to or above 1.25. The summed value is a wide U-like shape, here designed to be asymmetric. Obviously, when in a particular period the real exchange rate is mostly high (1.10 or more, in the example), a positive exposure will appear from the tests; but in another subperiod a negative relation may surface, and in the long run there may seem to be no correlation at all,

\footnotetext{
${ }^{6}$ The local slope is $2 \delta_{m, t}\left(S_{t}-\underline{S}_{m, t}\right)_{-}$, with the negative sign coming from $\left(S_{t}-\underline{S}_{m, t}\right)_{-}$rather than from $\delta_{m, t}$.
} 
unconditionally, between $V$ and $S$.

We study differences in value to avoid an integrated (unit-root) left-hand side variable, but it remains important to keep the level of the exchange rate in the picture when modeling a dynamically exposed firm. For every division $f \in\{x, m\}$ we identify the change as

$$
\Delta\left(S_{t}-\underline{S}_{f}\right)^{2}=2\left(S_{t-1}-\underline{S}_{f}\right)_{\ldots} \Delta S_{t}+\left(\Delta S_{t}\right)^{2}
$$

Below, we write the value change of the firm's export-like activities. Adding a similar term for the $m$ divisions, we then obtain the value changes for the exposed units taken together:

$$
\begin{aligned}
\Delta V_{x, t}= & \Delta \gamma_{x, t}+\delta_{x, t}\left[2\left(S_{t-1}-\underline{S}_{x, t}\right)+\Delta S_{t}\right] \mathbf{1}_{S_{t-1}>\underline{S}_{x, t}} \Delta S_{t}, \\
\Delta V_{m, t}= & \Delta \gamma_{m, t}+\delta_{m, t}\left[2\left(S_{t-1}-\underline{S}_{m, t}\right)+\Delta S_{t}\right] \mathbf{1}_{S_{t-1}<\underline{S}_{m, t}} \Delta S_{t}, \\
\Delta\left(V_{x, t}+V_{m, t}\right)=\Delta \gamma_{x, t}+\Delta \gamma_{m, t} & +\delta_{x, t}\left[2\left(S_{t-1}-\underline{S}_{x, t}\right)+\Delta S_{t}\right] \mathbf{1}_{S_{t-1}>\underline{S}_{x, t}} \Delta S_{t} \\
& +\delta_{m, t}\left[2\left(S_{t-1}-\underline{S}_{m, t}\right)+\Delta S_{t}\right] \mathbf{1}_{S_{t-1}<\underline{S}_{m, t}} \Delta S_{t},
\end{aligned}
$$

For empirical applications we have to specify how the exposures $\delta$ and the alternative values $\gamma$ behave over time. Two feasible options are to assume them either constant over time or proportional to the lagged total value. We go for constant critical exchange rates $\underline{S}_{f}$, and proportional parameters for the alternative asset values $\gamma$ and the exposures $\delta$ :

$$
\underline{S}_{m, t}=\underline{S}_{m} ; \underline{S}_{x, t}=\underline{S}_{x} ; \gamma_{m, t}+\gamma_{x, t}=\gamma V_{t-1} ; \quad \delta_{m, t}=\delta_{m} V_{t-1} ; \quad \delta_{x, t}=\delta_{x} V_{t-1}
$$

Below, we switch to returns:

$$
\begin{aligned}
r_{t}:= & \frac{\Delta V_{t}}{V_{t-1}}=\frac{\Delta V_{d, t}}{V_{t-1}}+\frac{\Delta V_{x, t}}{V_{t-1}}+\frac{\Delta V_{m, t}}{V_{t-1}}, \\
= & \left.\frac{V_{d, t-1}}{V_{t-1}} \frac{V_{d, t}-V_{d, t-1}}{V_{d, t-1}}+\gamma \frac{V_{t-1}-V_{t-2}}{V_{t-1}}+\delta_{x}\left[2\left(S_{t-1}-\underline{S}_{x}\right)+\Delta S_{t}\right)\right] \Delta S_{t} \mathbf{1}_{S_{t-1}>\underline{S}_{x}} \\
& +\delta_{m}\left[2\left(S_{t-1}-\underline{S}_{m}\right)+\Delta S_{t}\right] \Delta S_{t} \mathbf{1}_{S_{t-1}<\underline{S}_{m}} .
\end{aligned}
$$

Finally, we include a domestic market-model term as a simple way to account for domestic activities and general asset-pricing effects. The domestic market exposure coefficient is allowed to change depending on what happens in the exchange markets affecting the relative importance of the domestic activities in the total firm value $\left(V_{d, t-1} / V_{t-1}\right)$. For the moment, we denote this time-varying market coefficient as $\beta_{t}$ and report the reader to Subsection 2.3 for the exact parametrization of $\beta_{t}$ as a function of $S_{t-1} \cdot 2.3:^{7}$ Including also an intercept, this leads to our

\footnotetext{
${ }^{7}$ Note that $\beta_{t}$ is estimating the market sensitivity of the firm as a whole, not just the home divisions. For instance, the value of the international activities is partly determined by changes in interest rates, which induces a correlation with the domestic market index.
} 
most general model for the firm's currency exposure:

$$
\begin{aligned}
r_{t}= & \left.\alpha+\beta_{t} r_{t}^{M}+\gamma \tilde{r}_{t-1}+\delta_{x}\left[2\left(S_{t-1}-\underline{S}_{x}\right)+\Delta S_{t}\right)\right] \Delta S_{t} \mathbf{1}_{S_{t-1}>\underline{S}_{x}} \\
& +\delta_{m}\left[2\left(S_{t-1}-\underline{S}_{m}\right)+\Delta S_{t}\right] \Delta S_{t} \mathbf{1}_{S_{t-1}<\underline{S}_{m}}+\varepsilon_{t},
\end{aligned}
$$

where $\tilde{r}_{t-1}=\left(V_{t-1}-V_{t-2}\right) / V_{t-1}$ and $\varepsilon_{t}$ is the error term.

For many firms, as mentioned, one or two of the deltas may have zero values. With two strictly positive $\delta$, the firm or sector is actually ambidextrous, having sometimes a predominantly export orientation and sometimes a predominantly import-like character. If only one $\delta$ is positive and the other zero, in contrast, the firm or sector is either export- or importoriented, not both. In either case there also is an interest as to at what kind of critical levels $\underline{S}_{f}$ the international ambitions are abandoned totally. Specifically, the question is where these critical rates are located relative to the feasible range of real-exchange-rate levels and relative to each other. Economically, this depends on whether trade is just an option to the firm or, instead, a sine qua non for survival. Statistically, the issue is whether there are three, two or one regime in the dynamic model.

\subsection{Three-, two- and one- regime versions of the Dynamic Exposure Model (DEM): economic and statistical interpretation}

Suppose, for instance, that next to exports there is viable domestic market for the firm's output. When the foreign exchange rate is sufficiently low, exporters do suspend trade; but since domestic sales are possible, such a decision would not mean the firm has to be liquidated. Thus, trading may be suspended, but that would still not mean that the option to ever trade again at some future point is entirely worthless, in the same way as non-exercising an Americanstyle call option does not mean the option has zero value. ${ }^{8}$ It remains conceivable that, later, the firm might re-enter the export business. Likewise, in some sectors an importing firm can potentially switch to domestic sourcing, given the right exchange rate. If that is the case, the importer may suspend trade, but the option to switch back to imports later is not abandoned once and forever. In either case, trading is not a sine qua non for the firm's survival, and the option to (ever) trade again does not really become worthless at any realistic exchange rate. Thus, in many potential or actual export sectors, $\underline{S}_{x}$ would be so low that this level has not been reached during the sample period and will almost surely never be reached in future: the

\footnotetext{
${ }^{8}$ The analogy is far from perfect. The option to trade is not just American, but also perpetual and reversible.
} 
export option always remain relevant, for now or for the future. Likewise, in some potential or actual import sectors $\underline{S}_{m}$ may be so high that it was never reached in the sample and will almost surely never be reached in future: the idea to import never becomes totally irrelevant.

The model, which we label "Dynamic Exposure Model" (DEM) can be tested as a three-, two- or -one-regime model. In the actual estimations we start from three regimes, and reduce the number of regimes whenever the estimates suggest that a less flexible model does not entail a significant loss in explanatory power.

\subsubsection{Three-regime model: both options to trade can realistically become worth- less}

The three-regime model holds when, in Equation (13), both critical rates $\underline{S}_{m}$ and $\underline{S}_{x}$ are well inside the range of observed real exchange rates. That is, this three-regime model means that, by our estimates, the option to trade has actually been abandoned irrevocably during the sample period.

Two $\delta$ s are estimated and should turn out to be positive. The three regimes are ( $i$ - high exchange rates) the export-side option is valuable, the import one is not (ii - low exchange rates) the import-side option is valuable, the import one is not; (iii - elsewhere) either both options have value, or none has, depending on whether $\underline{S}_{m}$ exceeds $\underline{S}_{x}$ (like in Figure 1) or not.

(iii.a) In the former case, the firm is ambidextrous in the middle zone, but one (and only one) type of trade may become irrelevant for higher or lower exchange rates.

(iii.b) In the latter case, this is a relatively closed sector where the prospect of trade becomes a speck in the sky only for rather low or high rates, and the two are never relevant simultaneously.

\subsubsection{Two-regime models: trade is an option in one direction only}

When one of the two critical rates is estimated to be outside the observed range, then in this sample one option to trade never loses value: firms do have domestic alternatives and therefore never have to liquidate (i.e. irrevocably abandon their international options). In the two-regime case this domestic alternative is available at one side only. For instance, if the 
option to export is never utterly abandoned we have $\mathbf{1}_{S_{t-1}>\underline{S}_{x}}=1, \forall S$, and therefore

$$
\begin{aligned}
r_{t}=\alpha+\beta_{t} r_{t}^{M} & \left.+\gamma \tilde{r}_{t-1}+\delta_{x}\left[2\left(S_{t-1}-\underline{S}_{x}\right)+\Delta S_{t}\right)\right] \Delta S_{t} \\
& +\delta_{m}\left[2\left(S_{t-1}-\underline{S}_{m}\right)+\Delta S_{t}\right] \Delta S_{t} \mathbf{1}_{S_{t-1}<\underline{S}_{m}}+\epsilon_{t} . \\
=\alpha+\gamma \tilde{r}_{t-1} & \left.+\left(\delta_{m}+\delta_{x}\right)\left[2\left(S_{t-1}-\underline{S}_{a}\right)+\Delta S_{t}\right)\right] \Delta S_{t} \mathbf{1}_{S_{t-1}<\underline{S}_{m}} \\
& +\delta_{x}\left[2\left(S_{t-1}-\underline{S}_{x}\right)+\Delta S_{t}\right] \Delta S_{t} \mathbf{1}_{S_{t-1}>\underline{S}_{m}}+\beta r_{m}+\epsilon_{t} .
\end{aligned}
$$

where $\underline{S}_{a}:=\left(\delta_{m} \underline{S}_{m}+\delta_{x} \underline{S}_{x}\right) /\left(\delta_{m}+\delta_{x}\right)$, the average critical rate. In contast, if the option to import is the one that is never utterly abandoned we have $\mathbf{1}_{S_{t-1}<\underline{S}_{m}}=1, \forall S$, and therefore

$$
\begin{aligned}
r_{t}=\alpha+\beta_{t} r_{t}^{M} & \left.+\gamma \tilde{r}_{t-1}+\delta_{x}\left[2\left(S_{t-1}-\underline{S}_{x}\right)+\Delta S_{t}\right)\right] \Delta S_{t} \mathbf{1}_{S_{t-1}>\underline{S}_{x}} \\
& +\delta_{m}\left[2\left(S_{t-1}-\underline{S}_{m}\right)+\Delta S_{t}\right] \Delta S_{t}+\epsilon_{t} . \\
=\alpha+\beta_{t} r_{t}^{M} & +\gamma \tilde{r}_{t-1}+\delta_{m}\left[2\left(S_{t-1}-\underline{S}_{m}\right)+\Delta S_{t}\right] \Delta S_{t} \mathbf{1}_{S_{t-1}<\underline{S}_{x}} \\
& \left.+\left(\delta_{m}+\delta_{x}\right)\left[2\left(S_{t-1}-\underline{S}_{a}\right)+\Delta S_{t}\right)\right] \Delta S_{t} \mathbf{1}_{S_{t-1}>\underline{S}_{x}}+\epsilon_{t} .
\end{aligned}
$$

Both regressions look very similar in that they predict a different value for delta depending on whether $S$ is below or above some critical rate. The tell-tale difference is that in Equation (14) we should observe the higher delta for low exchange rates, while in Equation (15) the higher should occur for high rates. If we cannot reject inequality of the two estimated slopes, then one can accept the hypothesis that one of the deltas is zero (a monodextrous firm).

\subsubsection{The one-regime models: firms always have an important domestic alterna- tive}

The model becomes even simpler if there is no switch at all. This could be true for a monodextrous sector whose option to trade never becomes worthless. The one-regime model also emerges for an ambidextrous firm which never gives up either of its options, or at least not for rates observed in the sample: both $\underline{S}_{f}$ s are outside the observed range of real exchange rates. In this case all observations are assumed to be inside the middle domain of the general model, and the model simplifies to

$$
\begin{aligned}
r_{t}= & \left.\alpha+\beta_{t} r_{t}^{M}+\gamma \tilde{r}_{t-1}+\delta_{x}\left[2\left(S_{t-1}-\underline{S}_{x}\right)+\Delta S_{t}\right)\right] \Delta S_{t} \\
& \left.+\delta_{m}\left[2\left(S_{t-1}-\underline{S}_{m}\right)+\Delta S_{t}\right]\right] \Delta S_{t},+\epsilon_{t}, \\
= & \left.\alpha+\beta_{t} r_{t}^{M}+\gamma \tilde{r}_{t-1}+\left(\delta_{m}+\delta_{x}\right)\left[2\left(S_{t-1}-\underline{S}_{a}\right)+\Delta S_{t}\right]\right] \Delta S_{t}+\epsilon_{t} .
\end{aligned}
$$

There is no way to fully disentangle the export and import sides. Since there is no change of regime, we can observe just the sum of the deltas and cannot check whether both deltas are 
Table 1: Classification of models on the basis of $\underline{S}_{f}$, assuming $\delta>0$.

\begin{tabular}{lll} 
observation & model's interpretation & label \\
\hline$S_{\text {min }}<\underline{S}_{-}<\underline{S}_{+}<S_{\max }$ & $S_{\min }<\underline{S}_{m}<\underline{S}_{x}<S_{\max }$ & 3R MX closed \\
$S_{\min }<\underline{S}_{+}<\underline{S}_{-}<S_{\max }$ & $S_{\min }<\underline{S}_{x}<\underline{S}_{m}<S_{\max }$ & 3R MX ambi \\
$\underline{S}_{+}<S_{\min }<\underline{S}_{-}<S_{\max }$ & $\underline{S}_{x}<S_{\min }<\underline{S}_{m}<S_{\max }$ & 2R Mswitch \\
$S_{\min }<\underline{S}_{+}<S_{\max }<\underline{S}_{-}$ & $S_{\text {min }}<\underline{S}_{x}<S_{\max }<\underline{S}_{m}$ & 2R Xswitch \\
$\underline{S}_{+}<S_{\min }<S_{\max }<\underline{S}_{-}$ & $\underline{S}_{x}<S_{\min }<S_{\max }<\underline{S}_{m}$ & 1R
\end{tabular}

Key In the first column we list the possible positions of the two critical rates or knot points (initially labeled $\underline{S}_{+}$and $\underline{S}_{-}$, referring to the "larger than" and "smaller than" dummies they are associated with) relative to the highest and lowest observed rates $S_{\min }$ and $S_{\max }$. Then we show the tentative interpretation of these rates when the $\delta$ s are positive, and lastly the model label.

nonzero or not, that is, whether this is an ambidextrous case or not. But if the estimated value of $\underline{S}_{a}$, the delta-weighted average of the two critical rates, is low (below the lowest observed exchange rate), then the export divisions is likely to be dominant and vice versa.

Up to now, we have assumed that the switching behavior in the value of the export and import options are the only sources of threshold effects in the relation between equity returns and the foreign exchange rate. In practice, there may be other reasons for threshold effects, and the results in Section 3 suggest that in our sample this actually is the case quite often. For this reason, in the estimation equations of Section 2 we replace the $\underline{S}_{x}$ and $\underline{S}_{m}$ symbols of the model equations (13)-(16) with more neutral versions, $\underline{S}_{+}$and $\underline{S}_{-}$depending on whether they are associated with the "larger than" or "smaller than" dummies. Also the deltas are re-labeled in this way. When all coefficients have the expected sign, we then associate the estimates $\underline{S}_{+}$and $\underline{S}_{-}$with $\underline{S}_{x}$ and $\underline{S}_{m}$, respectively, and similarly for the deltas.

Table 1 summarizes the taxonomy. In the first column we list the possible positions of $\underline{S}_{+}$ and $\underline{S}_{-}$relative to the highest and lowest observed rates $S_{\min }$ and $S_{\max }$. Then we show the interpretation of these rates under our approach, and lastly the model label.

\subsection{Flexible Fourrier Form modeling of time-varying beta}

A final feature of our model is that changes in exchange rates lead to changes in the fraction of total firm value that is generated by the domestic activities $\left(V_{d, t-1} / V_{t-1}\right)$. The direct impact on the model equation (13) is that the domestic market exposure coefficient $\beta_{t}$ depends on the exchange rate and can be time-varying. Our model does not yield any particular specification for this dependence, except that if $\underline{S}_{m}<S_{t-1}<\underline{S}_{x}$ it should be a constant. We have 
considered several possible specifications for $\beta_{t}$ and found the Fourrier Flexible Form (FFF) of Gallant (1981) the most elegant. It specifies the unknown function $\beta_{t}=b\left(S_{t-1}\right)$ as a Fourrier series representation that includes additionally a second-order polynomial in the explanatory variables:

$$
\begin{aligned}
\beta_{t}= & \beta_{0}+\beta_{x, 0} s_{t-1} \mathbf{1}_{S_{t-1}>\underline{S}_{x}}+\beta_{m, 0} s_{t-1} \mathbf{1}_{S_{t-1}<\underline{S}_{m}}+\beta_{x, 1} s_{t-1}^{2} \mathbf{1}_{S_{t-1}>\underline{S}_{x}}+\beta_{m, 1} s_{t-1}^{2} \mathbf{1}_{S_{t-1}<\underline{S}_{m}} \\
& +\sum_{i=1}^{p} \beta_{x, 1+i} \cos \left(i s_{t-1}\right) \mathbf{1}_{S_{t-1}>\underline{S}_{x}}+\beta_{x, 1+2 p+i} \sin \left(i s_{t-1}\right) \mathbf{1}_{S_{t-1}>\underline{S}_{x}} \\
& \quad+\beta_{m, 1+i} \cos \left(i s_{t-1}\right) \mathbf{1}_{S_{t-1}<\underline{S}_{m}}+\beta_{m, 1+2 p+i} \sin \left(i s_{t-1}\right) \mathbf{1}_{S_{t-1}<\underline{S}_{m}}
\end{aligned}
$$

with $s_{t}$ a standardized version of $S_{t}$, such that $s_{t}$ is between 0 and $2 \pi$, which is needed for the FFF methodology to work. In our application, $S_{t}$ is the effective exchange rate series of Canada, Germany, Japan, U.K. and U.S over the period 1990-2010. This series is always less than two. Hence we set $s_{t}=\pi S_{t}$ in the application. Because of the second order polynomial, fewer trigonometric functions are needed to achieve a given level of accuracy (Gallant, 1981). In the empirical application, we set $p=2 .{ }^{9}$ Note that, given $\underline{S}_{x}$ and $\underline{S}_{m}$, the model is linear in the regression coefficients, which makes the model still relatively easy to estimate.

\section{Empirical procedure}

We evaluate the gains in goodness of fit of the dynamic exposure model against the log-linear model of Jorion on two data sets. The first series we investigate is the 1990-2010 monthly returns of industry indices of Canada, Germany, Japan, U.K. and U.S. The stock market index data are downloaded from Bloomberg and are all market weighted. The market index is proxied by the SPTSX, DAX, TOPIX, ASX and S\&P 500 for Canada, Germany, Japan, U.K. and U.S., respectively. Under the Bloomberg sector classification, there are 18 sectors for Canada and Germany, 29 for the U.K., 31 for Japan and 58 for the S\&P 500. The second return series we study is the 1990-2010 monthly returns of firms belonging to the S\&P 500 on July 31, 2010. Excluding the series with missing observations leads to a total of 116 stocks in 9 sectors. The exchange rate is taken as the close price of the IMF's CPI-based real effective exchange rate for the country at the end of month, and the risk-free rate is the IMF's Treasury bill rate in percent per annum.

For each series we first estimate the regression specifications corresponding to the models

\footnotetext{
${ }^{9}$ In case of quasi-multicollinearity one of the strongly correlated regressors is removed from the specification.
} 
in Table $1 .^{10}$ The goodness of fit of each of these models is evaluated through a Bayesian type of information criterion, that was designed by Gonzalo and Pitarakis (2002) to select across multiple threshold models. More precisely, when the model has $p$ parameters and $T$ observations resulting in a residual sum of squares $R S S_{T}$, the information criterion recommended by Gonzalo and Pitarakis is:

$$
B I C=\log R S S_{T}+p \frac{\log T}{T} .
$$

This criterion penalizes large models more than Akaike's criterion for which the penalty is $2 p / T$.

Chan (1993) and Hansen (2000) establish the super-fast convergence of threshold parameters like our $\underline{S}_{x}, \underline{S}_{m}$. Under general assumptions, Hansen (2000) even shows that the estimation uncertainty of $\underline{S}_{x}$ and $\underline{S}_{m}$ and $\underline{S}$ can be ignored when computing the asymptotic variance of the slope parameters $\left(\alpha, \beta, \zeta, \gamma, \delta_{+}, \delta_{-}\right)^{\prime}$ (conditional on knowing the number of regimes). We therefore compute standard errors of the slope estimators using the standard Newey-West estimator of the parameter covariance matrix.

Because of the non-linearity in the regression specification, standard gradient-based procedures to non-linear least squared estimation are likely to be flawed because of local optima. To avoid this, we use a global optimization routine, called differential evolution, in order to obtain the least squares estimates. Note that, given the threshold parameters, the regression becomes a linear function of the parameters. Hence it is possible to concentrate out all other regression parameters from the expression of the residual sum of squares and only optimize over the threshold parameters. This leads to a reliable and computationally convenient estimation procedure.

\section{Results}

From the description of the models (Section 1) and the estimation procedure (Section 2) the following caveats are in order. First, the diagnostic descriptions in Section 1 of course assume that the piecewise quadratic model is correct. In reality, the estimated critical $\underline{S}_{f} \mathrm{~s}$ where the quadratic's slope becomes zero may be way off the true smooth-pasting point, notably

\footnotetext{
${ }^{10}$ To ensure identifiability, we imposed the following parameter space restrictions. A first natural restriction is that $\underline{S}_{m}, \underline{S}_{x}>0$. In the estimation of the $2 \mathrm{R}$ Mswitch model, we further impose $\underline{S}_{m}<2$. While this value amply exceeds the highest number observed in our real-rate data, the restriction is still needed for identification. Indeed, note that, for large values of $\underline{S}_{m}$, the variable $2\left(S_{t-1}-\underline{S}_{m}\right)+\Delta S_{t} \approx \underline{S}_{m}$ and the coefficient $\delta_{m}$ is no longer unique identified.
} 
if the true functional relation is not well captured by our quadratics, especially at extreme values of the exchange rate, and/or is changing over time. A second sobering thought is that some critical values are quite close to the highest or lowest observed values of $S$, meaning that some regimes have just a few observations and that some observed terms $\left(S_{t}-\underline{S}_{+}\right)_{+}$or $\left(S_{t}-\underline{S}_{-}\right)_{-}$are almost behaving like dummies for extreme observations. It could be objected that, if we have few observations and/or little variation in the regressors for a certain regime, a significance test would still tell us whether the estimate is to be seriously or not. But the problem with this riposte is that, at this stage, these threshold values are just point estimates without identified confidence intervals. ${ }^{11}$ Relatedly, the estimated $\delta$ s etc take the estimated critical $\underline{S}_{f}$ s and the number of regimes as given. While the references cited above suggest this may be asymptotically correct, the effect still is that the standard errors for the deltas, by ignoring the uncertainties about the estimated critical $\underline{S}_{f} \mathrm{~s}$, might be too narrow in a finite sample like ours. For these reasons, our findings below are to be read as exploratory rather than as hard facts.

These caveats are most relevant if the ambition is to use the regressions to reliably classify each sector into the 3R, 2R-Xswitch or 2R-Mswitch categories. But about the main qualitative findings we feel much more confident: first, there seem to be plenty of non-linear features in the data; and second, disconcertingly few of the non-linear patterns seem to correspond to one of the models proposed here. Below, we flesh out both claims.

The more detailed results are available in Appendix tables 2-6. For the reader's convenience, Tables 2 and 3 summarize some key qualitative features of these results for each sample. In Table 2, which deals with national sector-index data, Panel A documents the occurence of non-linearities, and provides tallies for each class of models (1-, 2- or 3-regime DEMs, for instance). For the latter purpose we classify the models just on the basis of the position of the knot points relative to the sample range, as in Table 1, ignoring the values of the deltas at this stage.

The results in Panel A show that, among the 145 relations we estimated, not one opts for the standard loglinear regression as statistically attractive, in the BIC sense, compared to a DEM: in all cases, the drop of explanatory power when going from a DEM model to the standard loglinear version is too substantial. The column " $1 \mathrm{R}$ ", next, has zero entries too.

\footnotetext{
${ }^{11}$ For the single threshold model, a method to construct confidence bands is proposed by Hansen (2000) based on inverting the likelihood ratio test, but its extension to a multiple threshold model is not obvious.
} 
Table 2: Distribution of models for sector returns, grouped by country.

\begin{tabular}{|c|c|c|c|c|c|c|c|c|}
\hline \multicolumn{9}{|c|}{ Panel A: Classification on basis of $\underline{S}_{f}$} \\
\hline Country & $\begin{array}{c}\text { 3R MX } \\
\text { closed }\end{array}$ & $\begin{array}{c}\text { 3R MX } \\
\text { ambi }\end{array}$ & $\begin{array}{c}2 \mathrm{R} \\
\text { Mswitch }\end{array}$ & $\begin{array}{c}2 \mathrm{R} \\
\text { Xswitch }\end{array}$ & $1 \mathrm{R}$ & $\begin{array}{l}\text { log- } \\
\text { linear }\end{array}$ & & Nsectors \\
\hline Canada & 9 & 9 & 0 & 0 & 0 & 0 & & 18 \\
\hline Germany & 8 & 10 & 1 & 0 & 0 & 0 & & 19 \\
\hline Japan & 6 & 22 & 1 & 1 & 0 & 0 & & 30 \\
\hline UK & 5 & 23 & 0 & 1 & 0 & 0 & & 29 \\
\hline US & 17 & 32 & 0 & 0 & 0 & 0 & & 49 \\
\hline All & 45 & 96 & 2 & 2 & 0 & 0 & & 145 \\
\hline \multicolumn{9}{|c|}{ Panel B: Classification on basis of $\underline{S}_{f}$ and sign of $\delta \mathrm{s}$} \\
\hline Country & $\begin{array}{c}\text { 3R MX } \\
\text { closed }\end{array}$ & $\begin{array}{c}\text { 3R MX } \\
\text { ambi }\end{array}$ & $\begin{array}{c}2 \mathrm{R} \\
\text { Mswitch }\end{array}$ & $\begin{array}{c}2 \mathrm{R} \\
\text { Xswitch }\end{array}$ & $1 \mathrm{R}$ & $\begin{array}{c}\text { log- } \\
\text { linear }\end{array}$ & other & Nsectors \\
\hline Canada & 9 & 9 & 0 & 0 & 0 & 0 & 0 & 18 \\
\hline Germany & 6 & 10 & 0 & 0 & 0 & 0 & 3 & 19 \\
\hline Japan & 3 & 16 & 1 & 1 & 0 & 0 & 9 & 30 \\
\hline UK & 5 & 20 & 0 & 0 & 0 & 0 & 4 & 29 \\
\hline US & 15 & 28 & 0 & 0 & 0 & 0 & 6 & 49 \\
\hline All & 38 & 83 & 1 & 1 & 0 & 0 & 22 & 145 \\
\hline
\end{tabular}

Key: XMS refers to export-import switch, MS to import switch, XS to export switch, and $n \mathrm{R}$ to " $n$ regimes". The number of regimes is unity plus the number of estimated critical rates $\underline{S}_{f}$ that fall in the observed range of exchange rates.

In Panel A, the classification of r-regimes models into export- and import-switch is based on whether the outof-sample estimated $\underline{S}_{f}$ is below or above the observed range. In the second panel, we also look at the slopes and classify all equations where at least one delta has the wrong sign as "other".

That is, the relationship between $V$ and $S$ is not captured by a single quadratic either: we always need some semi-spline feature, with either one single knot point (the $2 \mathrm{R}$ models) or two (the $3 \mathrm{R}$ cases).

When we look at the types of models that do seem to do well, the following tentative conclusions emerge. First, almost all semi-splines seem to be of the three-regime type, suggesting that the quadratic approximation changes shape at least twice. Within that group, the "ambi" variant dominates two to one (96 to 45, out of 145). That is, there is less evidence of "semiclosed" sectors, exposed only at extreme rates and with a zone of middling exchange rates where the sector seems to be unaffected by forex markets. Rather, the middle zone looks like a domain where two relations overlap. The two-regime semi-spline is a very distant second: in 4 out of 145 cases, there seems to be an exposed stretch, petering out into an unexposed one within the range of observed exchange rates. M- and X-switch versions are equally represented.

When we next bring the signs of the deltas into the picture. In the appendix tables, all series that lead to at least one negative delta (at the 5\% significance level) are marked with a " $\times$ " sign, and their tallies are summarized in Panel B of Table 2. We see that 20 out of 141 of the 3-regime models actually reject the hypothesis that the deltas are positive, signaling a 
Table 3: Distribution of models for S\&P 500 stock returns, grouped by sector.

Panel A: Classification on basis of $\underline{S}_{f}$

\begin{tabular}{lcccccc|c} 
& $\begin{array}{c}3 \mathrm{R} \text { MX } \\
\text { Sector }\end{array}$ & $\begin{array}{c}3 \mathrm{R} \text { MX } \\
\text { ambi }\end{array}$ & $\begin{array}{c}2 \mathrm{R} \\
\text { Mswitch }\end{array}$ & $\begin{array}{c}2 \mathrm{R} \\
\text { Xswitch }\end{array}$ & \begin{tabular}{c} 
lR \\
Consumer Discret. \\
\cline { 2 - 7 } linear
\end{tabular} & Nfirms \\
Consumer Staples & 5 & 14 & 0 & 0 & 0 & 0 & 19 \\
Energy & 3 & 9 & 1 & 0 & 0 & 0 & 13 \\
Financials & 1 & 5 & 0 & 0 & 0 & 0 & 6 \\
Healthcare & 3 & 11 & 0 & 0 & 0 & 0 & 14 \\
Industrials & 4 & 9 & 0 & 1 & 0 & 0 & 14 \\
Information Tech. & 3 & 12 & 0 & 0 & 0 & 0 & 17 \\
Materials & 1 & 5 & 0 & 0 & 0 & 0 & 6 \\
Utilities & 3 & 8 & 0 & 0 & 0 & 0 & 11 \\
\hline All Panel B: Classification on basis of $\underline{S}_{f}$ and sign of $\delta \mathbf{s}$ & & 116
\end{tabular}

\begin{tabular}{lccccccc|c} 
Sector & $\begin{array}{c}3 \mathrm{R} \text { MX } \\
\text { closed }\end{array}$ & $\begin{array}{c}3 \mathrm{R} \text { MX } \\
\text { ambi }\end{array}$ & $\begin{array}{c}2 \mathrm{R} \\
\text { Mswitch }\end{array}$ & $\begin{array}{c}2 \mathrm{R} \\
\text { Xswitch }\end{array}$ & $\begin{array}{c}\text { log- } \\
1 \mathrm{R}\end{array}$ & $\begin{array}{l}\text { linear } \\
\text { other }\end{array}$ & Nfirms \\
\hline Consumer Discret. & 4 & 7 & 0 & 0 & 0 & 0 & 8 & 19 \\
Consumer Staples & 3 & 9 & 1 & 0 & 0 & 0 & 0 & 13 \\
Energy & 1 & 5 & 0 & 0 & 0 & 0 & 0 & 6 \\
Financials & 3 & 11 & 0 & 0 & 0 & 0 & 0 & 14 \\
Healthcare & 3 & 7 & 0 & 0 & 0 & 0 & 4 & 14 \\
Industrials & 5 & 11 & 0 & 0 & 0 & 0 & 1 & 17 \\
Information Tech & 3 & 8 & 3 & 0 & 0 & 0 & 2 & 16 \\
Materials & 1 & 4 & 0 & 0 & 0 & 0 & 1 & 6 \\
Utilities & 2 & 6 & 0 & 0 & 0 & 0 & 3 & 11 \\
\hline All & 25 & 68 & 4 & 0 & 0 & 0 & 19 & 116
\end{tabular}

Key: XMS refers to export-import switch, MS to import switch, XS to export switch, and $n \mathrm{R}$ to " $n$ regimes". The number of regimes is unity plus the number of estimated critical rates $\underline{S}_{f}$ that fall in the observed range of exchange rates.

In Panel A, the classification of r-regimes models into export- and import-switch is based on whether the outof-sample estimated $\underline{S}_{f}$ is below or above the observed range. In the second panel, we also look at the slopes and classify all equations where at least one delta has the wrong sign as "other".

concave or partly concave relation that does not fit in with our theoretical logic. The failure rate, one out of seven, is about the same in the two subgroups of $3 \mathrm{R}$ models. We relegate the economic interpretation to the concluding section; at this point we just note that in a non-trivial minority of cases there is either a serious flaw in our modeling of the options to trade, or an entirely different logic is at work. This problem is absent in Canada, remains rare in the US too, but arises rather strongly in Japan; ${ }^{12}$

While a failure rate of one out of seven is not dramatic, especially for a model that makes

\footnotetext{
${ }^{12}$ The wayward behavior of the Japanese series is puzzling. One (untested) conjecture is that, for export kings like those two, the market factor actually loads heavily on export companies and picks up a non-trivial part of the exchange-rate effect, non-linearities and all, so that our model for the non-linearities, being imperfect, cannot capture the concavities anymore.
} 
strong assumptions about the stability of the relationship, it still raises the question whether the aggregation implicit in sector-index data might not be one of the causes. Also the predominance of three-regime models may be due to aggregation. But the sample of 116 SP-500 firms does not bring a fundamentally different picture, as the digest in Table 3 shows. Again, three-regime models dominate totally (with 111 out of 116 cases), and within this class, the middle domain appears to be of the overlapping-curve type rather than the no-exposure type (83 against 28). The loglinear or one-regime model is never selected. And when we finally turn to the sign of the deltas, the rejection rate is slightly higher than for the index data, at one out of six rather than one out of seven. Thus, aggregation across firms seems to explain neither the predominance of three-regime models nor the more-than-occasional occurrence of concavity patterns.

\section{Discussion and conclusion}

The good news, in a sense, is that the semi-spline or DEM model seems to be very successful at unearthing deviations from the loglinear model, hitherto the workhorse in this literature. The bad news, however, is that it is bringing up somewhat too many patterns that are unexpected under the option-to-trade logic. In many cases, the 'other' model suggests a monotone relation, but with a partly convex, partly concave pattern rather than the smoothly convex relations one expects for importers or exporters, respectively.

What could be the reason? Monotone relations could mean the firms are monodextrous with a simple structure, but our regression specification is too flexible; that is, the wobblylooking relation might be due to overfitting. Another factor that could be obscuring the patterns might be selective hedging. If the firm covers all or part of its currency exposure only under certain circumstances, then in some zones of the observed $S$ s the slope may be much weaker than elsewhere. But why this leads to concave-looking relations is not that obvious. A third avenue could be an equally hard-to-model feature: the relations shift over time because the firm's chosen technology is changing. For instance, the data for low $S$ s may predominantly correspond to a smaller plant size than the data for high $S$ s. In short, it is fair to conclude, we think, that more work is needed here.

A second finding is that, at least in our data, the patterns are not very different between sectoral and individual-firm data. Perhaps that is less surprising firms that stayed in the SP500 for 20 years must be rather big and therefore heterogenous too. A next step then would be to consider a sample of smaller firms. 
Equities' Exposures to Currencies

\section{References}

Adler, M., Dumas, B., 1983, International Portfolio Choice and Corporation Finance: A synthesis, The Journal of Finance, 38, 925-984

Adler, M., Dumas, B., 1984. Exposure to currency risk: denition and measurement. Financial Management Summer, 41-50.

Adler, M., Dumas, B., Simon, D., 1986 Winter. Exchange risk surprises in international portfolios. Journal of Portfolio Management, 44-53.

Allayannis, G., 1995. Time-variation of the exchange rate exposure: an industry analysis. Working paper, New York University.

Allayannis, G., 1996. Exchange rate exposure revisited. NYU Working Paper, New York University.

Amihud, Y., 1994. Exchange rates and the valuation of equity shares. In: Amihud, Y., Levich, R.M. (Eds.), Exchange rates and corporate performance. Irwin, New York, 49-59.

Bartov, E., Bodnar, G.M., 1994. Firm valuation, earnings expectations, and the exchange rate exposure effect. Journal of Finance, 49: 1755-1785.

Bodnar, G.M., Gentry, W.M., 1993. Exchange rate exposure and industry characteristics: evidence from Canada, Japan and the USA. Journal of International Money and Finance, 12: 29-45.

Bodnar, G.M.,Wong, M.H.F., 2003. Estimating exchange rate exposures: issues in model structure. Financial Management, 32: 35-67.

Carter, David A., Pantzalis, Christos and Simkins, Betty J., Asymmetric Exposure to ForeignExchange Risk: Financial and Real Option Hedges Implemented by U.S. Multinational Corporations (February 14, 2003). Available at SSRN: http://ssrn.com/abstract $=387082$.

Carter, David A., Pantzalis, Christos and Simkins, Betty J., Firmwide Risk Management of Foreign Exchange Exposure by U.S. Multinational Corporations (January 8, 2001). Available at SSRN: http://ssrn.com/abstract $=255891$.

Chamberlain, S., Howe, J.S., Popper, H., 1997. The exchange rate exposure of US and Japanese banking institutions. Journal of Banking and Finance, 21: 871-889.

Chan, K.S., 1993. Consistency and Limiting Distribution of the Least Squares Estimator of a Threshold Autoregressive Model. Annals of Statistics, 21: 520-533.

Choi, J.J., Prasad, A.M., 1995. Exchange risk sensitivity and its determinants: a rm and industry analysis of US multinationals. Financial Management, 24: 77-88.

Chow, E.H., Chen, H.-L., 1998. The determinants of foreign exchange rate exposure: evidence on Japanese firms. Pacific- Basin Finance Journal, 6: 153-174.

Chow, E.H., Lee, W.Y., Solt, M.E., 1997b. The exchange-rate risk exposure of asset returns. Journal of Business, 70: 105-123.

Chue, T.K. and D. Cook. 2008. Emerging market exchange rate exposure. Journal of Banking and Finance 32(7), 1349-1362.

Crabb, P. R., 2002. Multinational corporations and hedging exchange rate exposure. International Review of Economics and Finance, 11(3), 299-314

De Jong, A., Ligterink, J. and Macrae, V. (2006), A Firm-Specific Analysis of the Exchange-Rate Exposure of Dutch Firms. Journal of International Financial Management and Accounting, 17:128.

De Santis, G., Gerard, B., 1998. How big is the premium for currency risk? Journal of Financial Economics, 49: 375-412.

Di Iorio, A., Faff, R., 2000. An analysis of asymmetry in foreign currency exposure of the Australian equities market. Journal of Multinational Financial Management, 10: 133-159.

Dixit, A., 1993. The art of smooth pasting. Harwood Academic Publishers, 72pp 
Dominguez, K.M.E., Tesar, L.L., 2001b. Trade and exposure. American Economic Review, Papers and Proceedings, 91: 367-370.

Doukas, J., Hall, P.H., Lang, L.H.P., 1999. The pricing of currency risk in Japan. Journal of Banking and Finance, 23: 1-20.

Doukas, J., Hall, P.H., Lang, L.H.P., 2003. Exchange rate exposure at the firm and industry level. Financial Markets, Institutions and Instruments, 12: 291-346.

Dumas, B., 1978. The theory of the trading firm revisited. Journal of Finance, 33: 1019-1029.

Dumas, B., Solnik, B., 1995. The world price of foreign exchange risk. Journal of Finance, 50: 445-479.

Entorf, H., Jamin, G., 2002. German stock returns: the Dance with the Dollar. Working paper

Entorf, H., Jamin, G., 2004. German exchange rate exposure at DAX and aggregate level, international trade, and the role of exchange rate adjustment costs. . German Economic Review 8(3) 344-374

Fraser, S., Pantzalis, C., 2004. Foreign exchange rate exposure of US multinational corporations: a firm-specific approach. Journal of Multinational Financial Management, 14: 261-281.

Frisch, R. and F. Waugh, 1933, Partial time regressions as compared with individual trends, Econometrica, 45, 939-953.

Gallant, R.G., 1981. On the Bias in Flexible Functional Forms and an Essentially Unbiased Form: The Fourier Flexible Form, Journal of Econometrics 15: 211-245.

Gao, T., 2000. Exchange rate movements and the profitability of US multinationals. Journal of International Money and Finance, 19: 117-134.

Glaum, M., Brunner, M., Holger, H., 2000. The DAX and the dollar: the economic exchange rate exposure of German corporations. Journal of International Business Studies, 31: 715-724.

Gonzalo, J. and J-Y Pitarakis, 2002. Estimation and model selection based inference in single and multiple threshold models. Journal of Econometrics 110: 319352.

Griffin, J.M., Stulz, R.M., 2001. International competition and exchange rate shocks: a cross-country industry analysis of stock returns. Review of Financial Studies, 14: 215-241.

Hansen, B., 2000. Sample splitting and threshold estimation, Econometrica 68, 575-603.

He, J., Ng, L., 1998. The foreign exchange exposure of Japanese multinational corporations. Journal of Finance, 53: 733-753.

Johnson, L.L., 1960: The theory of hedging and speculation in commodity futures, Review of Economic Studies 27, 139-151

Jorion, P., 1990. The exchange rate exposure of US multinationals. Journal of Business, 63: 331-345.

Jorion, P., 1991. The pricing of exchange rate risk in the stock market. Journal of Financial and Quantitative Analysis, 26: 363-376.

Khoo, A., 1994. Estimation of foreign exchange exposure: an application to mining companies in Australia. Journal of International Money and Finance, 13: 342-363.

Kiymaz, H., 2003. Estimation of foreign exchange exposure: an emerging market application. Journal of Multinational Financial Management, 13: 71-84.

Miller, K.D., Reuer, J.J., 1998. Firm strategy and economic exposure to foreign exchange rate movements. Journal of International Business Studies, 29: 493-514.

Muller, A., Verschoor, W.F.C., 2006a. European foreign exchange risk exposure. European Financial Management, 12: 195-220.

Muller, A., Verschoor W., 2006b. Foreign exchange risk exposure: Survey and suggestions. European Financial Management, 16: 385-410.

Muller, A., Verschoor, W.F.C., 2006c. Asymmetric foreign exchange risk exposure: evidence from US multinationals. Journal of empirical finance, 13: 495-518. 
Priestley, R. and Odegaard, B.A., 2007. Linear and nonlinear exchange rate exposure. Journal of International Money and Finance, 26: 1016-1037.

Sercu, P. 1980. A generalization of the international CAPM. (Journal de l'Association Française de) Finance, 1(1), 91-135

Sercu, P., 2009. International business finance: theory into practice. Princeton University Press, 2009.

Sercu, P. and C. Van Hulle, 1992. Exchange rate volatility, international trade, and the value of exporting firms. Journal of Banking and Finance, 16(1), 155-182.

Sohnke M. B, G. W. Brown and B. A. Minton. 2010. Resolving the exposure puzzle: the many facets of exchange rate exposure. Journal of Financial Economics, 95(2), pp. 148-173.

Solnik, B. 1973. European Capital Markets, Lexington Books, 1973.

Stein, J.L. 1961, The simultaneous determination of spot and futures prices, American Economic Review 51, 1012-1025

Williamson, R.G., 2001. Exchange rate exposure and competition: evidence from the automotive industry. Journal of Financial Economics, 59: 441-475.

\section{Appendix Tables}


Table 4: Canada (Over the sample: $0.840 \leq S_{t} \leq 1.298$ ).

\begin{tabular}{|c|c|c|c|c|c|c|c|c|}
\hline & selectedmodels & $\mathrm{Sx}$ & $\mathrm{Sm}$ & $\delta_{x} / \delta / \zeta$ & pvalue & $\delta_{m} / \eta$ & pvalue & other \\
\hline bank & 3R MX ambi & 1.194 & 1.21 & 4.305 & 0.112 & 0.433 & 0.374 & \\
\hline capitalgoods & 3R MX closed & 1.251 & 1.243 & 11.678 & 0.657 & -0.262 & 0.565 & \\
\hline consumer.durables.apparel & 3R MX closed & 1.219 & 1.107 & 18.9 & 0.029 & 2.415 & 0.136 & \\
\hline consumer.service & 3R MX ambi & 0.927 & 1.244 & 1.444 & 0.063 & 0.037 & 0.944 & \\
\hline diversified.financial & 3R MX ambi & 1.199 & 1.202 & 6.932 & 0.213 & 0.19 & 0.632 & \\
\hline energy & 3R MX closed & 1.234 & 1.233 & -2.162 & 0.85 & -0.465 & 0.276 & \\
\hline food.staples & 3R MX ambi & 0.936 & 1.21 & 1.001 & 0.039 & 0.501 & 0.258 & \\
\hline Food.beverage.tobacco & 3R MX closed & 1.199 & 1.124 & 5.255 & 0.062 & 0.232 & 0.75 & \\
\hline household.personal.products & 3R MX closed & 1.228 & 1.107 & 21.822 & 0.759 & 2.879 & 0.021 & \\
\hline insurance & 3R MX ambi & 1.159 & 1.234 & -3.776 & 0.166 & -0.448 & 0.3 & \\
\hline materials & 3R MX ambi & 1.207 & 1.297 & -5.575 & 0.198 & -0.187 & 0.589 & \\
\hline media & 3R MX closed & 1.035 & 0.928 & -0.096 & 0.907 & 1.385 & 0.702 & \\
\hline real.estate & 3R MX closed & 1.225 & 1.139 & 2.524 & 0.658 & 0.579 & 0.511 & \\
\hline retailing & 3R MX closed & 1.211 & 1.202 & -8.556 & 0.192 & 1.044 & 0.038 & \\
\hline software.services & 3R MX ambi & 0.914 & 0.915 & -0.251 & 0.784 & 0.588 & 0.978 & \\
\hline telecommunication & 3R MX closed & 1.212 & 1.21 & 2.921 & 0.732 & 0.081 & 0.805 & \\
\hline transportation & 3R MX ambi & 1.202 & 1.247 & 2.85 & 0.459 & -0.442 & 0.299 & \\
\hline utilities & 3R MX ambi & 1.072 & 1.237 & 0.572 & 0.492 & 0.224 & 0.442 & \\
\hline
\end{tabular}

Key: $n \mathrm{R}$ means there seem to be " $n$ regimes". The estimated number of regimes is unity plus the number of estimated critical rates $\underline{S}_{f}$ that fall in the observed range of exchange rates. The classification of r-regimes models into export- and import-switch is based on whether the out-of-sample estimated $\underline{S}_{f}$ is below or above the observed range. In the last column, a " $\times$ " signals a significantly negative delta (at $\alpha=0.05$ ), which is incompatible with the model's logic.

Table 5: Germany (Over the sample: $0.821 \leq S_{t} \leq 1.092$ ).

\begin{tabular}{rcrrrrrrr}
\hline & selectedmodels & $\mathrm{Sx}$ & $\mathrm{Sm}$ & $\delta_{x} / \delta / \zeta$ & pvalue & $\delta_{m} / \eta$ & pvalue & other \\
\hline auto & 3R MX ambi & 0.989 & 0.997 & 7.463 & 0.069 & 0.029 & 0.971 & \\
bank & 2R Mswitch & 0 & 0.979 & -0.702 & 0.011 & -7.594 & 0.002 & $\times$ \\
chemicals & 3R MX closed & 1.022 & 0.966 & 6.704 & 0.364 & -1.294 & 0.018 & $\times$ \\
media & 3R MX closed & 0.984 & 0.945 & -1.366 & 0.869 & 0.184 & 0.939 & \\
basic resources & 3R MX ambi & 0.99 & 1.006 & -6.233 & 0.26 & 0.27 & 0.768 & \\
food beverage & 3R MX ambi & 1.011 & 1.017 & -12.59 & 0.179 & 1.615 & 0.012 & \\
technology & 3R MX closed & 0.979 & 0.978 & -5.68 & 0.23 & 0.526 & 0.253 & \\
insurance & 3R MX ambi & 1.011 & 1.011 & 7.164 & 0.272 & 0.156 & 0.793 & \\
mansinary & 3R MX closed & 0.996 & 0.955 & 4.356 & 0.253 & 5.006 & 0 & \\
industrial & 3R MX ambi & 0.825 & 0.961 & 3.015 & 0.018 & 2.466 & 0.087 & \\
construction & 3R MX ambi & 0.993 & 0.995 & 3.527 & 0.268 & -1.353 & 0.18 & \\
pharm and healthcare & 3R MX closed & 1.007 & 1.006 & 20.768 & 0 & 1.483 & 0.056 & \\
software & 3R MX ambi & 0.955 & 0.995 & -1.315 & 0.638 & 1.733 & 0.163 & \\
telecommunication & 3R MX ambi & 1.022 & 1.04 & -17.415 & 0.262 & -0.551 & 0.705 & \\
financial service & 3R MX closed & 0.947 & 0.944 & -1.217 & 0.796 & 1.845 & 0.455 & \\
telecommunication & 3R MX ambi & 1.003 & 1.04 & 9.354 & 0.154 & 0.81 & 0.032 & \\
financial service & 3R MX closed & 0.971 & 0.97 & -3.326 & 0.448 & 1.473 & 0.128 & \\
consumer & 3R MX closed & 0.998 & 0.871 & 1.406 & 0.746 & -9.032 & 0 & $\times$ \\
\hline
\end{tabular}

Key: $n \mathrm{R}$ means there seem to be " $n$ regimes". The estimated number of regimes is unity plus the number of estimated critical rates $\underline{S}_{f}$ that fall in the observed range of exchange rates. The classification of r-regimes models into export- and import-switch is based on whether the out-of-sample estimated $\underline{S}_{f}$ is below or above the observed range. In the last column, a " $\times$ " signals a significantly negative delta (at $\alpha=0.05$ ), which is incompatible with the model's logic. 
Table 6: Japan (Over the sample: $0.660 \leq S_{t} \leq 1.249$ ).

\begin{tabular}{|c|c|c|c|c|c|c|c|c|}
\hline & selectedmodels & $\mathrm{Sx}$ & $\mathrm{Sm}$ & $\delta_{x} / \delta / \zeta$ & pvalue & $\delta_{m} / \eta$ & pvalue & other \\
\hline air transportation & 3R MX ambi & 0.783 & 0.896 & -0.057 & 0.882 & 1.199 & 0.191 & \\
\hline chemical & 2R Xswitch & 0.78 & 2 & -0.425 & 0.167 & -0.097 & 0.136 & \\
\hline construction & 3R MX ambi & 0.751 & 0.92 & -0.531 & 0.051 & -1.109 & 0.235 & \\
\hline electric applicance & 3R MX ambi & 0.672 & 0.778 & 0.747 & 0 & -0.114 & 0.95 & \\
\hline electric power\&gas & 3R MX ambi & 0.861 & 1.028 & -0.697 & 0.298 & 0.278 & 0.505 & \\
\hline fishery agri and forestry & 3R MX ambi & 0.797 & 1.153 & -1.197 & 0.003 & 0.018 & 0.953 & $\times$ \\
\hline food & 3R MX ambi & 0.781 & 0.802 & -0.697 & 0 & -0.295 & 0.755 & $\times$ \\
\hline glass and ceramics & 3R MX ambi & 0.783 & 0.788 & 0.279 & 0.299 & -1.882 & 0.255 & \\
\hline info\&communication & 3R MX ambi & 0.785 & 0.857 & -1.094 & 0.009 & 0.499 & 0.722 & $x$ \\
\hline insurance & 3R MX ambi & 0.781 & 0.789 & -0.438 & 0.205 & -0.767 & 0.586 & \\
\hline iron\&steel & 3R MX ambi & 0.785 & 1.015 & 0.553 & 0.249 & -0.218 & 0.718 & \\
\hline machinary & 3R MX ambi & 0.94 & 1.245 & -0.68 & 0.139 & -0.286 & 0.064 & \\
\hline marine transportation & 3R MX ambi & 0.912 & 0.971 & 0.897 & 0.35 & 0.151 & 0.884 & \\
\hline metal prod & 3R MX closed & 0.785 & 0.78 & -0.161 & 0.477 & -0.757 & 0.191 & \\
\hline mining & 3R MX ambi & 0.783 & 0.789 & -0.505 & 0.298 & 1.967 & 0.328 & \\
\hline security and commodity future & 3R MX ambi & 1.018 & 1.028 & -0.678 & 0.55 & -0.73 & 0.214 & \\
\hline nonferrous metals & 3R MX ambi & 0.787 & 0.857 & -0.077 & 0.822 & -1.609 & 0.122 & \\
\hline oil\&coal & 3R MX ambi & 0.78 & 1.07 & -0.181 & 0.668 & 0.745 & 0.171 & \\
\hline pharmaceutial & 3R MX closed & 0.994 & 0.78 & -0.77 & 0.544 & -4.022 & 0.148 & \\
\hline precision instruments & 3R MX ambi & 0.892 & 1.02 & 1.189 & 0.008 & -1.196 & 0.002 & $x$ \\
\hline real estate & 3R MX closed & 1.009 & 0.905 & -2.673 & 0.044 & -0.065 & 0.952 & $x$ \\
\hline land transport & 3R MX ambi & 0.783 & 0.97 & -0.772 & 0.003 & -0.214 & 0.593 & $x$ \\
\hline pulp\&paper & 3R MX ambi & 0.783 & 1.021 & -0.052 & 0.916 & 0.802 & 0.252 & \\
\hline retail & 3R MX closed & 0.787 & 0.786 & -0.536 & 0.012 & -2.849 & 0.263 & $x$ \\
\hline rubber & 3R MX ambi & 0.793 & 0.796 & 0.574 & 0.191 & -0.703 & 0.593 & \\
\hline service & 3R MX ambi & 0.785 & 0.788 & -0.568 & 0.022 & -2.277 & 0.01 & $x$ \\
\hline textile\&apparels & 3R MX closed & 0.786 & 0.78 & -0.145 & 0.586 & 0.607 & 0.723 & \\
\hline transportation equip & 2R Mswitch & 0 & 0.895 & 0.327 & 0 & 0.831 & 0.424 & \\
\hline warehousing harbor transporation serv & 3R MX closed & 0.788 & 0.785 & -1.172 & 0 & 1.598 & 0.353 & $\times$ \\
\hline wholesale & 3R MX ambi & 0.789 & 1.245 & -0.509 & 0.297 & -0.379 & 0.406 & \\
\hline
\end{tabular}

Key: $n \mathrm{R}$ means there seem to be " $n$ regimes". The estimated number of regimes is unity plus the number of estimated critical rates $\underline{S}_{f}$ that fall in the observed range of exchange rates. The classification of r-regimes models into export- and import-switch is based on whether the out-of-sample estimated $\underline{S}_{f}$ is below or above the observed range. In the last column, a " $\times$ " signals a significantly negative delta (at $\alpha=0.05$ ), which is incompatible with the model's logic. 
Table 7: United Kingdom (Over the sample: $0.935 \leq S_{t} \leq 1.335$ ).

\begin{tabular}{|c|c|c|c|c|c|c|c|c|}
\hline & selectedmodels & $\mathrm{Sx}$ & $\mathrm{Sm}$ & $\delta_{x} / \delta / \zeta$ & pvalue & $\delta_{m} / \eta$ & pvalue & other \\
\hline aerospace.defense & 3R MX ambi & 1.035 & 1.047 & -0.148 & 0.768 & -5.432 & 0.236 & \\
\hline automobiles.parts & 3R MX closed & 1.289 & 1.166 & -3.475 & 0.826 & 1.924 & 0.344 & \\
\hline banks & 3R MX ambi & 1.082 & 1.155 & -1.838 & 0.016 & 0.771 & 0.353 & $x$ \\
\hline beverages & 3R MX ambi & 1.035 & 1.04 & 0.321 & 0.332 & 0.616 & 0.858 & \\
\hline chemicals & 3R MX ambi & 1.091 & 1.166 & 0.268 & 0.575 & -0.04 & 0.968 & \\
\hline construction.materials & 3R MX ambi & 0.944 & 1.087 & 0.432 & 0.163 & -2.41 & 0.308 & \\
\hline electricity & 3R MX ambi & 1.039 & 1.279 & -0.825 & 0.119 & 0.137 & 0.766 & \\
\hline electronic.equipment & 3R MX closed & 1.028 & 1.027 & -0.112 & 0.862 & 9.589 & 0.252 & \\
\hline euity.investment.instruments & 2R Xswitch & 1.024 & 1.335 & 0.137 & 0.511 & -0.532 & 0.021 & $x$ \\
\hline financial.services & 3R MX ambi & 1.031 & 1.077 & -0.456 & 0.258 & -2.034 & 0.334 & \\
\hline telecommunications & 3R MX ambi & 1.035 & 1.276 & -0.145 & 0.774 & 1.701 & 0.01 & \\
\hline food.drug & 3R MX ambi & 1.046 & 1.166 & 0.128 & 0.779 & 3.244 & 0 & \\
\hline food.producers & 3R MX ambi & 1.011 & 1.026 & 0.486 & 0.054 & -0.975 & 0.885 & \\
\hline forestry.paper & 3R MX ambi & 1.261 & 1.319 & 2.151 & 0.861 & -1.003 & 0.341 & \\
\hline genera.industrials & 3R MX closed & 1.004 & 1.002 & 0.297 & 0.318 & 4.481 & 0.721 & \\
\hline general.retalers & 3R MX ambi & 1.024 & 1.298 & -0.047 & 0.889 & 0.099 & 0.826 & \\
\hline health.care & 3R MX ambi & 0.957 & 1.176 & -0.359 & 0.331 & -1.521 & 0.111 & \\
\hline engineering & 3R MX ambi & 1.04 & 1.154 & -0.154 & 0.608 & -2.622 & 0.024 & $x$ \\
\hline metals.mings & 3R MX ambi & 1.061 & 1.061 & -1.084 & 0.386 & -8.269 & 0.338 & \\
\hline transportation & 3R MX closed & 1.062 & 0.948 & -0.412 & 0.292 & -150.896 & 0.061 & \\
\hline leisure.goods & 3R MX ambi & 1.166 & 1.176 & 0.431 & 0.737 & -2.523 & 0.074 & \\
\hline life.insurance & 3R MX ambi & 1.024 & 1.092 & -0.578 & 0.132 & 0.841 & 0.684 & \\
\hline media & 3R MX ambi & 1.014 & 1.016 & 0.245 & 0.404 & 7.903 & 0.286 & \\
\hline minging & 3R MX ambi & 1.031 & 1.064 & 0.25 & 0.659 & -8.685 & 0.008 & $x$ \\
\hline oil.gas & 3R MX ambi & 1.031 & 1.062 & 0.74 & 0.003 & -5.219 & 0.084 & \\
\hline pharmaceuticals & 3R MX ambi & 1.047 & 1.049 & 0.815 & 0.149 & 2.536 & 0.516 & \\
\hline software.computer & 3R MX ambi & 1.027 & 1.031 & -0.259 & 0.476 & -1.46 & 0.776 & \\
\hline technology & 3R MX ambi & 1.025 & 1.031 & -0.493 & 0.074 & 2.255 & 0.683 & \\
\hline tobacco & 3R MX closed & 1.295 & 1.276 & -21.285 & 0.39 & -0.879 & 0.167 & \\
\hline
\end{tabular}

Key: $n \mathrm{R}$ means there seem to be " $n$ regimes". The estimated number of regimes is unity plus the number of estimated critical rates $\underline{S}_{f}$ that fall in the observed range of exchange rates. The classification of r-regimes models into export- and import-switch is based on whether the out-of-sample estimated $\underline{S}_{f}$ is below or above the observed range. In the last column, a " $\times$ " signals a significantly negative delta (at $\alpha=0.05$ ), which is incompatible with the model's logic. 
Table 8: United States (Over the sample: $0.857 \leq S_{t} \leq 1.149$ ).

\begin{tabular}{|c|c|c|c|c|c|c|c|c|}
\hline & selectedmodels & $\mathrm{Sx}$ & $\mathrm{Sm}$ & $\delta_{x} / \delta / \zeta$ & pvalue & $\delta_{m} / \eta$ & pvalue & other \\
\hline S5FDSRX & 3R MX ambi & 0.916 & 0.922 & -0.827 & 0.145 & 6.848 & 0.653 & \\
\hline S5AUTO & 3R MX closed & 0.983 & 0.982 & 0.364 & 0.83 & -1.809 & 0.783 & \\
\hline S5AUTC & 3R MX ambi & 0.982 & 1.06 & 1.559 & 0.254 & -1.464 & 0.401 & \\
\hline S5AIRFX & 3R MX ambi & 0.963 & 0.963 & -3.956 & 0.02 & 3.342 & 0.684 & $x$ \\
\hline S5AIRLX & 3R MX ambi & 0.965 & 1.101 & 2.183 & 0.113 & 4.556 & 0.006 & \\
\hline S5AEROX & 3R MX ambi & 0.88 & 0.951 & 0.83 & 0.094 & 0.809 & 0.929 & \\
\hline S5BEVG & 3R MX ambi & 0.932 & 0.965 & 1.174 & 0.031 & 0.419 & 0.955 & \\
\hline S5BIOTX & 3R MX closed & 1.045 & 1.041 & 4.181 & 0.361 & -7.161 & 0.113 & \\
\hline S5BUILX & 3R MX closed & 1.058 & 1.056 & -9.39 & 0.083 & -4.87 & 0.028 & $x$ \\
\hline S5CHEM & 3R MX closed & 1.031 & 0.947 & 4.003 & 0.023 & -7.189 & 0.278 & \\
\hline S5CFINX & 3R MX closed & 1.098 & 0.986 & 6.093 & 0.613 & -1.943 & 0.71 & \\
\hline S5CMPE & 3R MX closed & 0.965 & 0.902 & 4.07 & 0.006 & 66.344 & 0.263 & \\
\hline S5CSTMX & 3R MX ambi & 1.026 & 1.039 & -14.809 & 0.047 & -0.334 & 0.904 & $x$ \\
\hline S5CONP & 3R MX ambi & 0.88 & 1.101 & -0.73 & 0.26 & -0.829 & 0.592 & \\
\hline S5CBNK & 3R MX ambi & 1.035 & 1.115 & -4.708 & 0.079 & 0.108 & 0.925 & \\
\hline S5CSTEX & 3R MX closed & 1.082 & 0.876 & 6.126 & 0.527 & 620.574 & 0 & \\
\hline S5COMM & 3R MX ambi & 0.895 & 0.969 & 0.315 & 0.749 & -23.179 & 0.123 & \\
\hline S5DIVT & 3R MX ambi & 0.883 & 0.889 & -0.155 & 0.754 & -58.265 & 0.328 & \\
\hline S5ENRE & 3R MX ambi & 0.895 & 0.969 & 4.052 & 0 & -7.261 & 0.487 & \\
\hline S5ELEQ & 3R MX ambi & 0.969 & 1.021 & 0.202 & 0.861 & -6.349 & 0.012 & $x$ \\
\hline S5ELUTX & 3R MX closed & 0.981 & 0.936 & 2.542 & 0.007 & -2.561 & 0.782 & \\
\hline S5FDPR & 3R MX ambi & 0.964 & 1.098 & 0.965 & 0.209 & -0.199 & 0.886 & \\
\hline S5GASUX & 3R MX ambi & 0.864 & 1.136 & 2.362 & 0 & 1.063 & 0.407 & \\
\hline S5HODU & 3R MX closed & 0.981 & 0.903 & -2.392 & 0.042 & 32.959 & 0.238 & $x$ \\
\hline S5HOPRX & 3R MX ambi & 0.934 & 0.956 & 0.579 & 0.41 & 2.632 & 0.705 & \\
\hline S5HOTRX & 3R MX ambi & 1.026 & 1.033 & 1.021 & 0.59 & -2.93 & 0.09 & \\
\hline S5HCPS & 3R MX closed & 1.087 & 1.023 & -12.003 & 0.407 & 0.292 & 0.909 & \\
\hline S5HCEQ & 3R MX closed & 1.068 & 1.031 & -1.552 & 0.543 & -2.053 & 0.33 & \\
\hline S5INSUX & 3R MX closed & 1.089 & 1.06 & 0.319 & 0.962 & 2.219 & 0.107 & \\
\hline S5INDCX & 3R MX ambi & 0.859 & 0.895 & 0.872 & 0.041 & 14.954 & 0.713 & \\
\hline S5LEIS & 3R MX closed & 0.926 & 0.923 & 1.802 & 0.013 & -10.271 & 0.427 & \\
\hline S5MRET & 3R MX ambi & 0.932 & 0.965 & -1.446 & 0.112 & 8.004 & 0.241 & \\
\hline S5MEDAX & 3R MX ambi & 0.869 & 0.902 & -0.183 & 0.698 & 25.319 & 0.353 & \\
\hline S5MUTIX & 3R MX ambi & 0.876 & 0.966 & 1.047 & 0.197 & -1.682 & 0.925 & \\
\hline S5MACH & 3R MX closed & 1.087 & 0.947 & 11.604 & 0.042 & -0.489 & 0.94 & \\
\hline S5METL & 3R MX ambi & 0.947 & 1.115 & 1.092 & 0.383 & -4.924 & 0.002 & $x$ \\
\hline S5OFFEX & 3R MX ambi & 0.903 & 0.917 & 5.049 & 0 & -41.326 & 0.254 & \\
\hline S5PHARX & 3R MX closed & 0.975 & 0.947 & 1.048 & 0.221 & 5.328 & 0.55 & \\
\hline S5PERSX & 3R MX ambi & 0.932 & 0.96 & 3.452 & 0.002 & -8.566 & 0.267 & \\
\hline S5PAFO & 3R MX ambi & 0.904 & 0.947 & 0.884 & 0.316 & -15.885 & 0.146 & \\
\hline S5REITS & 3R MX ambi & 0.987 & 1.024 & 3.075 & 0.071 & -1.352 & 0.611 & \\
\hline S5ROAD & 3R MX closed & 1.092 & 0.932 & 18.91 & 0.001 & 6.869 & 0.482 & \\
\hline S5SSEQX & 3R MX ambi & 0.895 & 0.927 & 0.512 & 0.599 & 12.318 & 0.685 & \\
\hline S5SPRE & 3R MX closed & 0.965 & 0.902 & -2.025 & 0.153 & 57.878 & 0.062 & \\
\hline S5SOFT & 3R MX ambi & 0.88 & 0.902 & 0.56 & 0.534 & 116.706 & 0.077 & \\
\hline S5TEXA & 3R MX ambi & 0.895 & 1.101 & 0.228 & 0.798 & -1.296 & 0.439 & \\
\hline S5TOBAX & 3R MX ambi & 0.893 & 0.923 & 0.614 & 0.411 & 26.69 & 0.203 & \\
\hline S5INSSX & 3R MX ambi & 0.864 & 0.902 & 2.723 & 0.087 & 252.604 & 0.109 & \\
\hline S5INCR & 3R MX ambi & 1 & 1.084 & 7.797 & 0.033 & 0.752 & 0.867 & \\
\hline
\end{tabular}

Key: $n \mathrm{R}$ means there seem to be " $n$ regimes". The estimated number of regimes is unity plus the number of estimated critical rates $\underline{S}_{f}$ that fall in the observed range of exchange rates. The classification of r-regimes models into export- and import-switch is based on whether the out-of-sample estimated $\underline{S}_{f}$ is below or above the observed range. In the last column, a " $\times$ " signals a significantly negative delta (at $\alpha=0.05$ ), which is incompatible with the model's logic. 
Table 9: Consumer Discretionary (S\&P 500) (Over the sample: $0.857 \leq S_{t} \leq 1.149$ ).

\begin{tabular}{rcrrrrrrl}
\hline & selectedmodels & $\mathrm{Sx}$ & $\mathrm{Sm}$ & $\delta_{x} / \delta / \zeta$ & pvalue & $\delta_{m} / \eta$ & pvalue & other \\
\hline HRB & 3R MX closed & 1.099 & 1.012 & 38.534 & 0.071 & -3.751 & 0.481 & \\
CCL & 3R MX closed & 1.086 & 0.899 & -8.837 & 0.534 & 24.435 & 0.429 & \\
F & 3R MX ambi & 1.088 & 1.144 & -55.916 & 0.004 & -6.386 & 0.082 & $\times$ \\
GPS & 3R MX ambi & 0.869 & 0.932 & 0.725 & 0.729 & -13.544 & 0.93 & \\
GT & 3R MX ambi & 0.982 & 1.136 & -0.415 & 0.913 & -9.72 & 0.009 & $\times$ \\
HD & 3R MX closed & 0.965 & 0.963 & -1.491 & 0.443 & 13.104 & 0.408 & \\
IGT & 3R MX ambi & 0.974 & 1.13 & 1.7 & 0.651 & -6.153 & 0.017 & $\times$ \\
IPG & 3R MX ambi & 0.982 & 0.982 & 4.49 & 0.215 & -20.658 & 0.043 & $\times$ \\
LEG & 3R MX ambi & 0.968 & 1.097 & -1.003 & 0.639 & -4.253 & 0.066 & \\
LEN & 3R MX ambi & 1.084 & 1.088 & -42.5 & 0.009 & -4.322 & 0.246 & $\times$ \\
LOW & 3R MX ambi & 1.086 & 1.098 & -21.667 & 0.153 & 2.769 & 0.218 & \\
MCD & 3R MX ambi & 0.891 & 1.081 & 0.526 & 0.503 & -6.041 & 0.011 & $\times$ \\
MHP & 3R MX ambi & 0.964 & 1.118 & 2.231 & 0.218 & -3.14 & 0.071 & \\
MDP & 3R MX closed & 1.086 & 0.988 & -54.931 & 0 & 7.902 & 0.217 & $\times$ \\
JWN & 3R MX ambi & 0.953 & 1.088 & -2.907 & 0.225 & -4.991 & 0.177 & \\
RSH & 3R MX ambi & 0.879 & 0.965 & 2.423 & 0.216 & -3.98 & 0.739 & \\
TGT & 3R MX closed & 1.031 & 0.936 & -2.119 & 0.56 & 22.591 & 0.709 & \\
DIS & 3R MX ambi & 0.963 & 1.1 & 0.771 & 0.552 & -7.183 & 0.001 & $\times$ \\
WHR & 3R MX ambi & 0.982 & 0.983 & -0.091 & 0.981 & -1.762 & 0.793 & \\
\hline
\end{tabular}

Key: $n \mathrm{R}$ means there seem to be " $n$ regimes". The estimated number of regimes is unity plus the number of estimated critical rates $\underline{S}_{f}$ that fall in the observed range of exchange rates. The classification of r-regimes models into export- and import-switch is based on whether the out-of-sample estimated $\underline{S}_{f}$ is below or above the observed range. In the last column, a " $\times$ " signals a significantly negative delta (at $\alpha=0.05$ ), which is incompatible with the model's logic.

Table 10: Consumer Staples (S\&P 500) (Over the sample: $0.857 \leq S_{t} \leq 1.149$ ).

\begin{tabular}{rcrrrrrrr}
\hline & selectedmodels & $\mathrm{Sx}$ & $\mathrm{Sm}$ & $\delta_{x} / \delta / \zeta$ & pvalue & $\delta_{m} / \eta$ & pvalue & other \\
\hline CLX & 3R MX ambi & 0.932 & 0.953 & -0.704 & 0.316 & 26.43 & 0.054 & \\
KO & 3R MX ambi & 0.917 & 0.954 & 2.836 & 0.001 & -11.727 & 0.448 & \\
CCE & 3R MX closed & 0.936 & 0.934 & 3.16 & 0.203 & 4.435 & 0.857 & \\
COST & 3R MX ambi & 0.944 & 1.034 & -0.587 & 0.727 & -5.029 & 0.25 & \\
K & 3R MX ambi & 0.943 & 0.965 & 2.223 & 0.076 & -8.741 & 0.228 & \\
KR & 3R MX ambi & 1.062 & 1.104 & -8.765 & 0.16 & 0.079 & 0.962 & \\
MKC & 3R MX ambi & 0.901 & 1.028 & 0.425 & 0.691 & 4.695 & 0.098 & \\
TAP & 2R Mswitch & 0 & 1.021 & 0.579 & 0.011 & 5.311 & 0.263 & \\
PG & 3R MX ambi & 0.952 & 0.953 & 0.788 & 0.394 & -1.363 & 0.876 & \\
SYY & 3R MX closed & 1.065 & 0.936 & -0.43 & 0.946 & 9.741 & 0.438 & \\
HSY & 3R MX ambi & 0.925 & 0.931 & -0.628 & 0.4 & -14.587 & 0.422 & \\
WMT & 3R MX ambi & 0.933 & 1.082 & 0.435 & 0.706 & 1.988 & 0.36 & \\
WAG & 3R MX closed & 1.088 & 0.952 & -13.343 & 0.233 & 12.871 & 0.252 & \\
\hline
\end{tabular}

Key: $n \mathrm{R}$ means there seem to be " $n$ regimes". The estimated number of regimes is unity plus the number of estimated critical rates $\underline{S}_{f}$ that fall in the observed range of exchange rates. The classification of r-regimes models into export- and import-switch is based on whether the out-of-sample estimated $\underline{S}_{f}$ is below or above the observed range. In the last column, a " $\times$ " signals a significantly negative delta (at $\alpha=0.05$ ), which is incompatible with the model's logic. 
Table 11: Energy (S\&P 500) (Over the sample: $0.857 \leq S_{t} \leq 1.149$ ).

\begin{tabular}{rcrrrrrrr}
\hline & selectedmodels & Sx & Sm & $\delta_{x} / \delta / \zeta$ & pvalue & $\delta_{m} / \eta$ & pvalue & other \\
\hline CVX & 3R MX ambi & 0.891 & 1.1 & 0.356 & 0.535 & -1.593 & 0.179 & \\
COP & 3R MX ambi & 0.891 & 1.083 & 2.089 & 0.053 & 0.966 & 0.549 & \\
EOG & 3R MX ambi & 0.958 & 1.083 & 1.081 & 0.488 & 1.987 & 0.345 & \\
XOM & 3R MX closed & 1.024 & 1.023 & 4.235 & 0.053 & -0.523 & 0.827 & \\
SLB & 3R MX ambi & 0.953 & 0.982 & 5.442 & 0.001 & -4.926 & 0.566 & \\
SUN & 3R MX ambi & 0.921 & 0.99 & -0.737 & 0.639 & -4.243 & 0.409 & \\
\hline
\end{tabular}

Key: $n \mathrm{R}$ means there seem to be " $n$ regimes". The estimated number of regimes is unity plus the number of estimated critical rates $\underline{S}_{f}$ that fall in the observed range of exchange rates. The classification of r-regimes models into export- and import-switch is based on whether the out-of-sample estimated $\underline{S}_{f}$ is below or above the observed range. In the last column, a " $\times$ " signals a significantly negative delta (at $\alpha=0.05$ ), which is incompatible with the model's logic.

Table 12: Financials (S\&P 500) (Over the sample: $0.857 \leq S_{t} \leq 1.149$ ).

\begin{tabular}{rcrrrrrrr}
\hline & selectedmodels & $\mathrm{Sx}$ & $\mathrm{Sm}$ & $\delta_{x} / \delta / \zeta$ & pvalue & $\delta_{m} / \eta$ & pvalue & other \\
\hline AIG & 3R MX ambi & 1.062 & 1.062 & 15.304 & 0.524 & 5.18 & 0.01 & \\
AON & 3R MX closed & 0.963 & 0.953 & -0.865 & 0.463 & 8.408 & 0.592 & \\
BAC & 3R MX closed & 0.989 & 0.987 & -2.025 & 0.475 & 7.33 & 0.27 & \\
SCHW & 3R MX ambi & 0.966 & 1.046 & -2.237 & 0.292 & -8.547 & 0.159 & \\
C & 3R MX ambi & 0.988 & 0.989 & 2.964 & 0.246 & 2.709 & 0.656 & \\
HCP & 3R MX ambi & 0.964 & 1.011 & 2.088 & 0.164 & -0.61 & 0.841 & \\
JPM & 3R MX ambi & 0.902 & 0.926 & -0.869 & 0.536 & -7.233 & 0.799 & \\
LM & 3R MX ambi & 1.009 & 1.09 & -0.536 & 0.874 & -1.693 & 0.511 & \\
MMC & 3R MX ambi & 0.952 & 0.981 & -2.324 & 0.055 & 9.795 & 0.082 & \\
RF & 3R MX ambi & 0.984 & 1.033 & -4.96 & 0.077 & 1.277 & 0.652 & \\
SLM & 3R MX closed & 1.046 & 1.045 & 7.886 & 0.402 & 3.449 & 0.34 & \\
USB & 3R MX ambi & 1.031 & 1.053 & 0.247 & 0.935 & 2.156 & 0.522 & \\
VNO & 3R MX ambi & 1.009 & 1.018 & 0.763 & 0.772 & -3.343 & 0.085 & \\
WFC & 3R MX ambi & 1.016 & 1.116 & -1.878 & 0.473 & -2.263 & 0.23 & \\
\hline
\end{tabular}

Key: $n \mathrm{R}$ means there seem to be " $n$ regimes". The estimated number of regimes is unity plus the number of estimated critical rates $\underline{S}_{f}$ that fall in the observed range of exchange rates. The classification of r-regimes models into export- and import-switch is based on whether the out-of-sample estimated $\underline{S}_{f}$ is below or above the observed range. In the last column, a " $\times$ " signals a significantly negative delta (at $\alpha=0.05)$, which is incompatible with the model's logic. 
Table 13: Healthcare (S\&P 500) (Over the sample: $0.857 \leq S_{t} \leq 1.149$ ).

\begin{tabular}{rcrrrrrrc}
\hline & selectedmodels & $\mathrm{Sx}$ & $\mathrm{Sm}$ & $\delta_{x} / \delta / \zeta$ & pvalue & $\delta_{m} / \eta$ & pvalue & other \\
\hline AET & 3R MX ambi & 1.004 & 1.09 & -4.187 & 0.262 & -6.815 & 0.01 & $\times$ \\
AMGN & 3R MX ambi & 1.041 & 1.104 & -6.942 & 0.286 & -4.343 & 0.058 & \\
BAX & 3R MX ambi & 0.887 & 0.908 & 0.651 & 0.382 & -28.668 & 0.574 & \\
BMY & 3R MX ambi & 0.863 & 1.009 & -0.041 & 0.936 & -3.596 & 0.447 & \\
CAH & 3R MX ambi & 0.932 & 1.058 & 1.674 & 0.344 & 1.717 & 0.539 & \\
CERN & 3R MX ambi & 0.908 & 0.915 & -0.717 & 0.75 & -38.152 & 0.532 & \\
FRX & 3R MX closed & 0.952 & 0.951 & 0.32 & 0.908 & -8.376 & 0.535 & \\
HUM & 2R Xswitch & 0.936 & 2 & -9.53 & 0.1 & -1.883 & 0.007 & $\times$ \\
JNJ & 3R MX closed & 0.969 & 0.967 & 2.438 & 0.086 & 5.761 & 0.475 & \\
LLY & 3R MX ambi & 0.92 & 0.932 & 1.646 & 0.265 & -8.572 & 0.65 & \\
MRK & 3R MX closed & 1.115 & 1.058 & -124.062 & 0 & 2.61 & 0.379 & $\times$ \\
MYL & 3R MX ambi & 0.921 & 1.027 & 1.351 & 0.552 & -7.628 & 0.141 & \\
PFE & 2R Xswitch & 1.017 & 2 & -6.039 & 0.067 & -0.555 & 0.01 & $\times$ \\
STJ & 3R MX closed & 1.022 & 0.952 & -3.805 & 0.242 & -15.54 & 0.061 & \\
\hline
\end{tabular}

Key: $n \mathrm{R}$ means there seem to be " $n$ regimes". The estimated number of regimes is unity plus the number of estimated critical rates $\underline{S}_{f}$ that fall in the observed range of exchange rates. The classification of r-regimes models into export- and import-switch is based on whether the out-of-sample estimated $\underline{S}_{f}$ is below or above the observed range. In the last column, a " $\times$ " signals a significantly negative delta (at $\alpha=0.05$ ), which is incompatible with the model's logic.

Table 14: Industrials (S\&P 500) (Over the sample: $0.857 \leq S_{t} \leq 1.149$ ).

\begin{tabular}{rcrrrrrrr}
\hline & selectedmodels & $\mathrm{Sx}$ & $\mathrm{Sm}$ & $\delta_{x} / \delta / \zeta$ & pvalue & $\delta_{m} / \eta$ & pvalue & other \\
\hline AVY & 3R MX ambi & 0.917 & 1.035 & 0.621 & 0.644 & -0.459 & 0.887 & \\
BA & 3R MX ambi & 0.87 & 0.883 & 2.251 & 0.008 & 187.664 & 0.026 & \\
CAT & 3R MX ambi & 0.981 & 1.06 & 6.219 & 0.034 & 2.717 & 0.324 & \\
CSX & 3R MX closed & 1.067 & 0.936 & 14.752 & 0.053 & 22.106 & 0.076 & \\
CMI & 3R MX ambi & 0.921 & 1.144 & 0.396 & 0.885 & -2.268 & 0.445 & \\
DOV & 3R MX ambi & 0.916 & 1.142 & 1.799 & 0.237 & -1.496 & 0.447 & \\
FAST & 3R MX ambi & 0.92 & 0.963 & 0.374 & 0.817 & 1.574 & 0.877 & \\
GE & 3R MX ambi & 0.963 & 1.021 & 1.607 & 0.363 & -2.322 & 0.519 & \\
HON & 3R MX ambi & 0.917 & 0.926 & 2.713 & 0.051 & -34.657 & 0.209 & \\
LMT & 3R MX closed & 0.996 & 0.966 & 1.297 & 0.585 & 6.696 & 0.458 & \\
MAS & 3R MX ambi & 0.991 & 1.058 & 0.168 & 0.965 & -7.13 & 0.071 & \\
PCAR & 3R MX closed & 1.01 & 0.982 & 2.793 & 0.33 & 10.466 & 0.252 & \\
PBI & 3R MX ambi & 0.917 & 0.963 & -0.314 & 0.828 & 1.093 & 0.897 & \\
LUV & 3R MX closed & 1.035 & 0.937 & 11.09 & 0.066 & 31.835 & 0.04 & \\
TYC & 3R MX ambi & 0.861 & 0.879 & 0.786 & 0.563 & -1239.187 & 0 & $\times$ \\
UNP & 3R MX closed & 1.025 & 1.024 & 2.13 & 0.459 & 1.628 & 0.588 & \\
UTX & 3R MX ambi & 0.937 & 1.117 & 1.489 & 0.077 & -3.02 & 0.059 & \\
\hline
\end{tabular}

Key: $n \mathrm{R}$ means there seem to be " $n$ regimes". The estimated number of regimes is unity plus the number of estimated critical rates $\underline{S}_{f}$ that fall in the observed range of exchange rates. The classification of r-regimes models into export- and import-switch is based on whether the out-of-sample estimated $\underline{S}_{f}$ is below or above the observed range. In the last column, a " $\times$ " signals a significantly negative delta (at $\alpha=0.05$ ), which is incompatible with the model's logic. 
Table 15: Information Technology (S\&P 500) (Over the sample: $0.857 \leq S_{t} \leq 1.149$ ).

\begin{tabular}{rcrrrrrrr}
\hline & selectedmodels & $\mathrm{Sx}$ & $\mathrm{Sm}$ & $\delta_{x} / \delta / \zeta$ & pvalue & $\delta_{m} / \eta$ & pvalue & other \\
\hline ALTR & 3R MX ambi & 0.902 & 1.052 & -0.553 & 0.838 & -10.61 & 0.107 & \\
AAPL & 2R Mswitch & 0 & 0.932 & 0.778 & 0.008 & 49.189 & 0.094 & \\
AMAT & 3R MX closed & 1.058 & 0.947 & 14.653 & 0.024 & 10.86 & 0.594 & \\
CSCO & 3R MX ambi & 0.868 & 0.951 & 1.501 & 0.312 & -52.24 & 0.024 & $\times$ \\
DELL & 2R Mswitch & 0.857 & 1.064 & 3.336 & 0.059 & -0.573 & 0.886 & \\
HPQ & 3R MX ambi & 0.902 & 1.089 & -1.676 & 0.252 & -9.945 & 0.001 & $\times$ \\
INTC & 3R MX ambi & 0.932 & 0.952 & 3.77 & 0.028 & 0.265 & 0.99 & \\
IBM & 2R Mswitch & 0.163 & 1.064 & 0.809 & 0 & 0.771 & 0.801 & \\
MU & 3R MX ambi & 0.931 & 0.972 & 0.4 & 0.893 & -4.87 & 0.816 & \\
MSFT & 3R MX ambi & 0.947 & 0.972 & 5.673 & 0 & 11.147 & 0.31 & \\
MSI & 3R MX ambi & 0.947 & 1.097 & 3.126 & 0.113 & -4.846 & 0.102 & \\
NSM & 3R MX ambi & 0.951 & 0.952 & 4.21 & 0.111 & -42.099 & 0.077 & \\
ORCL & 3R MX closed & 0.901 & 0.894 & 4.657 & 0.002 & 350.994 & 0 & \\
SYMC & 3R MX closed & 1.119 & 0.88 & 308.165 & 0.024 & 143.494 & 0.532 & \\
TER & 3R MX ambi & 0.085 & 0.934 & 1.117 & 0.001 & 37.558 & 0.221 & \\
XRX & 3R MX ambi & 0.902 & 0.917 & 5.788 & 0.001 & -43.043 & 0.434 & \\
\hline
\end{tabular}

Key: $n \mathrm{R}$ means there seem to be " $n$ regimes". The estimated number of regimes is unity plus the number of estimated critical rates $\underline{S}_{f}$ that fall in the observed range of exchange rates. The classification of r-regimes models into export- and import-switch is based on whether the out-of-sample estimated $\underline{S}_{f}$ is below or above the observed range. In the last column, a " $\times$ " signals a significantly negative delta (at $\alpha=0.05$ ), which is incompatible with the model's logic.

Table 16: Materials (S\&P 500) (Over the sample: $0.857 \leq S_{t} \leq 1.149$ ).

\begin{tabular}{rcrrrrrrr}
\hline & selectedmodels & $\mathrm{Sx}$ & $\mathrm{Sm}$ & $\delta_{x} / \delta / \zeta$ & pvalue & $\delta_{m} / \eta$ & pvalue & other \\
\hline AA & 3R MX ambi & 0.947 & 1.091 & 1.196 & 0.418 & -5.243 & 0.064 & \\
BLL & 3R MX ambi & 0.936 & 0.968 & 1.177 & 0.347 & 13.467 & 0.126 & \\
DD & 3R MX ambi & 1.044 & 1.059 & 4.479 & 0.136 & 0.35 & 0.873 & \\
NUE & 3R MX ambi & 0.916 & 1.052 & -0.307 & 0.843 & -13.423 & 0 & $\times$ \\
SIAL & 3R MX ambi & 0.969 & 1.053 & 5.375 & 0.002 & 0.692 & 0.818 & \\
VMC & 3R MX closed & 1.079 & 1.012 & -23.808 & 0.204 & -3.923 & 0.33 & \\
\hline
\end{tabular}

Key: $n \mathrm{R}$ means there seem to be " $n$ regimes". The estimated number of regimes is unity plus the number of estimated critical rates $\underline{S}_{f}$ that fall in the observed range of exchange rates. The classification of r-regimes models into export- and import-switch is based on whether the out-of-sample estimated $\underline{S}_{f}$ is below or above the observed range. In the last column, a " $\times$ " signals a significantly negative delta (at $\alpha=0.05$ ), which is incompatible with the model's logic. 
Equities' Exposures to Currencies

Table 17: Utilities (S\&P 500) (Over the sample: $0.857 \leq S_{t} \leq 1.149$ ).

\begin{tabular}{rcrrrrrrc}
\hline & selectedmodels & $\mathrm{Sx}$ & $\mathrm{Sm}$ & $\delta_{x} / \delta / \zeta$ & pvalue & $\delta_{m} / \eta$ & pvalue & other \\
\hline CEG & 3R MX ambi & 1.111 & 1.144 & -224.222 & 0 & -1.798 & 0.227 & $\times$ \\
DUK & 3R MX ambi & 0.906 & 0.916 & 1.642 & 0 & 38.389 & 0.339 & \\
EIX & 3R MX ambi & 0.916 & 0.965 & 2.672 & 0.001 & 15.263 & 0.38 & \\
EXC & 3R MX closed & 0.96 & 0.959 & 2.81 & 0.074 & 8.557 & 0.159 & \\
TEG & 3R MX ambi & 1.017 & 1.018 & 2.739 & 0.05 & 1.479 & 0.634 & \\
NEE & 3R MX ambi & 0.926 & 0.953 & 2.669 & 0.001 & 4.072 & 0.578 & \\
POM & 3R MX ambi & 0.963 & 0.989 & 2.821 & 0.044 & -2.429 & 0.688 & \\
PPL & 3R MX ambi & 0.86 & 0.933 & 0.434 & 0.654 & 2.082 & 0.905 & \\
PGN & 3R MX closed & 1.031 & 0.932 & 1.508 & 0.345 & 5.335 & 0.677 & \\
SCG & 3R MX closed & 1.089 & 0.916 & -21.721 & 0.009 & 7.996 & 0.447 & $\times$ \\
TE & 3R MX ambi & 0.965 & 1.149 & 2.376 & 0.264 & -1.962 & 0.047 & $\times$ \\
\hline
\end{tabular}

Key: $n \mathrm{R}$ means there seem to be " $n$ regimes". The estimated number of regimes is unity plus the number of estimated critical rates $\underline{S}_{f}$ that fall in the observed range of exchange rates. The classification of r-regimes models into export- and import-switch is based on whether the out-of-sample estimated $\underline{S}_{f}$ is below or above the observed range. In the last column, a " $\times$ " signals a significantly negative delta (at $\alpha=0.05$ ), which is incompatible with the model's logic. 